James T. Neal

Sandia National Laboratories

Thomas R. Magorian

Amherst, New York

\title{
Robert L. Thoms
} AGM INC.

College Station, Texas

Whitney J. Autin and Richard P. McCulloh

Louisiana Geological Survey

Baton Rouge, Louisiana

\footnotetext{
Steven Denzler and Kathleen O. Byrne

Acres International Corporation

Amherst, New York
} 


\begin{abstract}
Anomalous features in Gulf Coast Salt domes exhibit deviations from normally pure sait and vary widely in form from one dome to the next, ranging considerably in length and width. They have affected both conventional and solution mining in several ways. Gas outbursts, insolubles, and potash (especially carnallite) have led to the breakage of tubing in a number of caverns, and caused irregular shapes of many caverns through preferential leaching. While not necessarily uncommon, such anomalous features essentially have limited the lateral extent of conventional mining at several salt mines, and led to accidents and even the closing of several other mines. Such anomalous features, and several others, are often aligned in anomalous zones, and appear to be related to diapiric processes of salt dome development. All the evidence indicates that anomalous zones are found between salt spines, where the differential salt intrusion accumulates other materials: anhydrite bands which are relatively strong, and other, weaker impurities. Shear zones and fault displacement detected at Big Hill and Weeks Island domes have not yet had any known adverse impacts on SPR oil storage, but new caverns at these sites conceivably may encounter some potentially adverse conditions. Seismic reflection profiles at Big Hill dome have shown numerous fractures and faults in the caprock, and verified the earlier recognition of a major shear zone transecting the entire salt stock and forming a graben in the overlying caprock. Casing that is placed in such zones can be at risk. Knowledge of these zones should create awareness of possible effects rather than preclude the future emplacement of caverns. To the extent possible, major anomalous zones and salt stock boundaries should be avoided, consistent with other factors and available acreage. Shear zones along overhangs may be particularly hazardous, and otherwise unknown valleys in the top of salt may occur along shear zones. These zones often can be mapped geophysically, especially with high-resoicition seismic techniques. The presence of anomalous zones may be suspected where relatively subtle surface topographic and/or hydrographic features such as lineations and slump features occur. Anomalous zones often will mark the boundaries between separate salt segments that exhibit differential movement within the salt stock.
\end{abstract}




\section{TABLE OF CONTENTS}

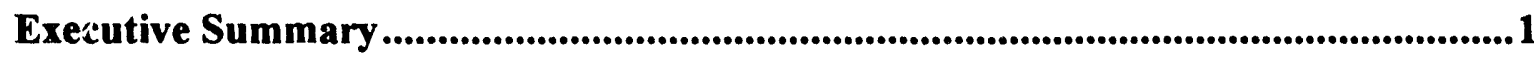

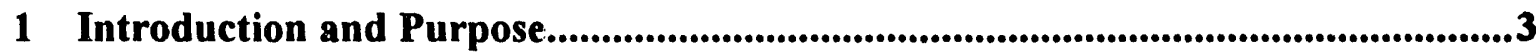

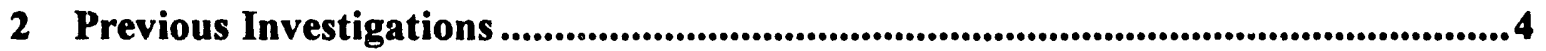

2.1 Description and Conceptualization of Anomalous Zones ..............................4

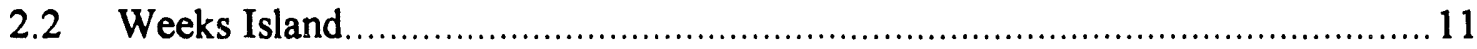

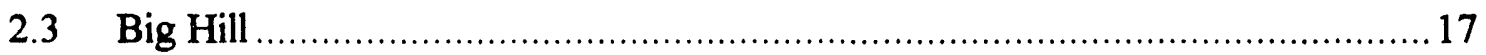

3 Surface Investigations............................................................................................. 18

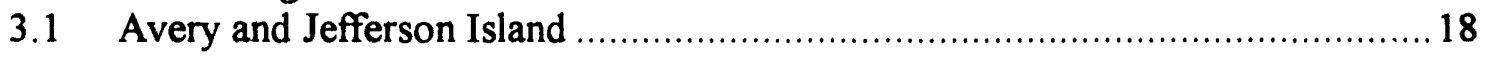

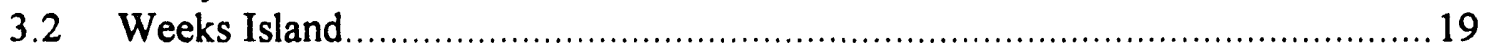

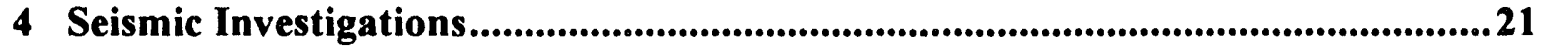

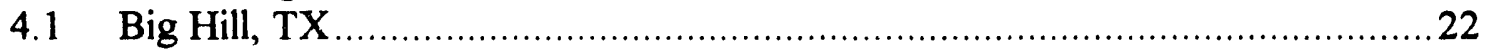

5 Effects of Anomalous Features on Solution Mining of Storage Caverns in Domal

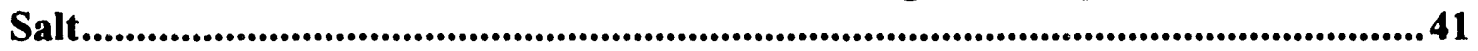

6 Conclusions .................................................................................................5 56

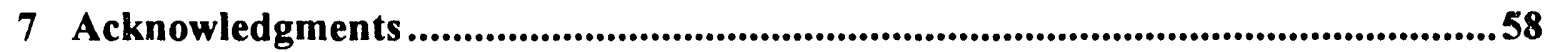

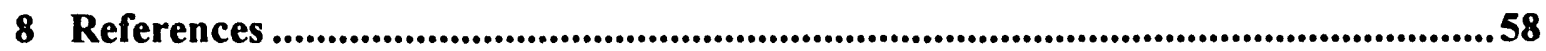

\section{TABLES AND FIGURES}

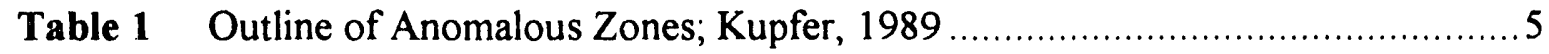

Figures 1a, b, and c Internal Structure and External Faults at SPR Sites: West Hackberry (1a), Bayou Choctaw (1b), and Big Hill (1c)

Figure 2 Anomalous Zones and Features at Weeks Island, LA

Figure 3 Internal Shear Zones and External Faults, Weeks Island, LA

Figure 4 Association of Surficial Sediments over Devils Backbone, Weeks Island .......20

Figure 5 Seismic "Caprock" Map

Figure 6 Recording and Display Parameters for Seismic Profiles, Figures 7-18. 
Figure 7 Dip Moveout Migration, Seismic Reflection Survey Line BH91-1, Big Hill Salt Dome, TX

Figure 8 STK Stack with Geologic Interpretation, Seismic Reflection Survey Line BH91-1, Big Hill Salt Dome, TX

Figure 9 Dip Moveout Migration, Seismic Reflection Survey Line BH91-2, Big Hill Salt Dome, TX

Figure 10 STK Stack with Geologic Interpretation, Seismic Reflection Survey Line BH91-2, Big Hill Salt Dome, TX

Figure 11 Dip Moveout Migration, Seismic Reflection Survey Line BH91-3, Big Hill Salt Dome, TX

Figure 12 STK Stack with Geologic Interpretation, Seismic Reflection Surrvey Line BH91-3, Big Hill Salt Dome, TX

Figure 13 Dip Moveout Migration, Seismic Reflection Survey Line BH91-4, Big Hill Salt Dome, TX

Figure 14 STK Stack with Geologic Interpretation, Seismic Reflection Survey Line BH91-4, Big Hill Salt Dome, TX

Figure 15 Dip Moveout Migration; Seismic Reflection Survey Line BH91-5, Big Hill Salt Dome, TX

Figure 16 STK Stack with Geologic Interpretation, Seismic Reflection Survey Line BH91-5, Big Hill Salt Dome, TX

Figure 17 Dip Moveout Migration, Seismic Reflection Survey Line BH91-TL, Big Hill Salt Dome, TX

Figure 18 STK Stack with Geologic Interpretation, Seismic Reflection Survey Line BH91-TL, Big Hill Salt Dome, TX.

Figure 19 Anomalous Features, Bryan Mound Salt Dome. $49-50$

Figure 20 Suggested Anomalous Zone, 1925 Surface Contours, and Anomalous Features, Bryan Mound Dome. 


\section{EXECUTIVE SUMMARY}

Anomalous features in salt domes are deviations from normally pure salt and take the form of impurities, compositional change, or physical property variation, and also may include major shearing. Several anomalous features may occur in combination and be aligned to constitute anomalous zones that are up to several hundred feet wide, and can extend for thousands of feet, even transecting entire domes. The latter occurrences are often related to regional tectonic structures which extend well beyond the immediate dome, whereas some features appear to be related only to the internal dynamics of individual domes. Thus anomalous zones are indicators of major boundaries and/or structural features, and do not necessarily have a common origin. However, the available evidence suggests that anomalous zones are typically the boundaries between salt spines, where the differential salt intrusion accumulates other materials.

Anomalous features were specifically investigated at Big Hill, TX, and Weeks Island, LA, with a view toward understanding their geological significance and suitability for additional cavern space. Seismic profiling was planned at each, but circumstances and timing precluded accomplishing this at Weeks Island. As an alternative, an investigation of surficial soil/geomorphic features was conducted at Weeks Island. The Big Hill profiling identified major structural features in the caprock, which presumably extend into the salt; they may have a bearing on the placement of additional caverns.

Anomalous features have been conceptualized as a result of many years of mapping in salt mines, and from logs and cores of many boreholes. Now that the nature and ubiquity of such features are better recognized, it is apparent that they are manifested at the surface in very subtle ways, such as topographic lineaments and sag ponds. The topographic expression at the surface usually implies differential motion within the salt mass, and the concept of separate salt spines is applicable. Other means of recognition involve geophysical imaging, such as high-resolution seismic reflection, or downhole logging methods to detect compositional variation.

Numerous cavern operators were canvassed and some agreed to share their experiences, provided that anonymity was maintained. We found that insolubles, potash, and gas were the principal features that had affected cavern development. Potash, especially carnallite, was the feature of main concern isd had caused many irregularly shaped caverns. 
Salt falls were sometimes the result of anhydrite layering, which would fall off in large blocks during leaching and damage casing strings. Gas releases apparently also led to salt falls in some caverns. Sand that has been identified within domal salt is almost exclusively found within anomalous zones. Major shear zones or faults in caprock may have led to some casing failure; consequently such locations should be avoided in the placement of new caverns.

The example of Bryan Mound was used to show how anomalous zones affected specific caverns there, especially abnormally abundant gas. Each of the other SPR sites also appear to have anomalous zones, and they have possibly elongated some cavern dimensions.

With respect to new sites and new cavern locations, knowledge of the occurrence of anomalous zones suggests that, in view of possible adverse effects, it is prudent to avoid them where possible, especially if they are near boundaries of spines, dome edges, or overhangs. In each of these cases the salt mass can be expected to possess salt of poorer quality than in the dome interior.

Where existing caverns are recognized to be located within or close to ancmalous zones, consideration should be given to special monitoring: reduced storage pressure and/or volume operation, or in the event of sustained loss of integrity, aban? snment. 


\section{INTRODUCTION AND PURPOSE}

Weeks Island, LA, and Big Hill, TX, salt domes are current Strategic Petroleum Reserve (SPR) storage sites that were considered as candidates for expansion of the SPR to one billion barrels [U. S. DOE, 1991]. Additional storage at both domes is possible by extending beyond existing property boundaries and creating new leached caverns.

Previous site characterization at Weeks Island [Acres, 1987] and Big Hill [Magorian and Neal, 1988] showed that probable anomalous zones exist at both domes, marked by highly-sheared salt adjacent to the main anomalous zone and the presence of sonic velocity discontinuities. Vertical displacement, i.e., faulting, is associated with these zones, resulting in measurable offsets of the salt (at Weeks Island) and overlying caprock (at Big Hill). These anomalous zones and those at other domes may be related to original discontinuities in the mother salt and/or differential movements of the salt mass during its diapiric intrusion from the mother salt at depth.

Investigations of other potential sites for SPR expansion found a number of anomalous zones and/or discontinuities, the largest and most conspicuous being at Stratton Ridge, TX, where the east side of the dome is cut by an active fault with vertical displacement up to 5000 $\mathrm{ft}$. Such conditions clearly preclude that part of the dome for storage development, and other parts of the dome have already experienced casing failures and loss of stored products. Major faults and shear zones in domes are anomalous departures from generally pure salt, but by themselves have not always been considered in the same category of features within anomalous zones.

The very nature of these zones is such that caverns created in them conceivably could develop asymmetries caused by preferential leaching. Or the introduction of foreign material (sand, shale) that is often associated with them could create leakage pathways (either into or out of the caverns) if there were appreciable permeability variation. Finally, additional physical displacements, e. g., faulting, could lead to the shearing of casing strings.

There has not been any known occurrence of anomalous zones affecting the safety of SPR storage caverns, but neither is it known conclusively what the specific effects on caverns have been. Their presence is suspected at several non-SPR domes, as an attempt to explain otherwise problematic features and behavior associated with cavern development [Thoms and 
Martinez, 1980]. The investigations reported on here attempt to define the nature, occurrence, and properties of these zones, and to examine Big Hill and Weeks Island domes, with the view of determining what safe offset, if any, is required for the prudent location of new solution-mined caverns.

\section{PREVIOUS INVESTIGATIONS}

\subsection{Descriptions and Conceptualization of Anomalous Zones}

"Anomalous feature" is the term coined by Kupfer [1980] to describe physical and structural deviations from generally pure salt, which typify many Gulf Coast salt domes, and especially the Five Island group in coastal Louisiana. These deviations often occur in linear to curvate zones of anomalous salt and may include the following features/properties:

(1) clastic materials, e. g., sand, (2) anhydrite concentrations, (3) shearing, (4) increased salt permeability, (5) reduced bulk density and/or sonic velocity, (6) recrystallization, (7) seeps of brine or hydrocarbons, (8) association with gas outbursts, (9) expansion joints, (10) slabbing, (11) black (or other color) salt. This list has been expanded upon and described in substantially more detail by Kupfer [1990]. Kupfer's 1989 outline (unpublished) is reproduced in Table 1 on the following page.

Generally, but not necessarily, three or more dissimilar features or properties will be associated together in an "anomalous zone." Kupfer [1990] indicates his experience shows that when three features are located, others are often found. These zones may be as narrow as a single $\sim 5 \mathrm{ft}$ dike of foreign material, or several hundred feet wide. The long dimensions vary widely from a few hundred feet to several thousand feet, and sometimes the entire breadth of a dome. Observation in a small number of underground mines has been the principal data source; consequently the entire dimensions of an anomalous zone have not been exposed. Other data has been derived from core samples, and from geophysical logs obtained in wells. Some circumstantial evidence also supports the interpretation of these features. The identification of anomalous features and the conceptualization of anomalous zones are fraught with similar difficulties as most classification schemes of natural systems; they should be treated as guides that are subject to further revision as new data and evidence become available.

Foreign sediments were first recognized in a Gulf Coast salt mine by G. S. Rogers at Avery Island [Heald, 1924], and this was apparently an isolated, anomalous feature because it 


\section{ANOMALOUS ZONES IN GULF COAST SALT DOMES \\ Donald H. Kupfer $11 / 89$}

\section{CHARACTERISTICS}

1. Each zone contains several anomalous salt properties ("anomalous features"). Zones cannot be characterized by any single property.

2. Zones are highly variable, lenticular, and discontinuous in detail; however, once established, they commonly have a predictable trend.

3. The individual "anomalous features" can occur alone (locally in pairs) over areas of various sizes and shapes. These "alone" occurrences are not anomalous zones.

4. Anomalous zones may be of any origin, and origin is not part of the definition. Typical origins include: primary (sedimentary), external "sheath" zone, separating two spines of salt, or caused by toroidal flow.

\section{IMPORTANCE}

The major importance of an anomalous zone is that it consists of various "anomalous features" distributed discontinuously along the zone. Thus if three or more anomalous properties are observed together, one should look for others.

The anomalous zones observed in the Gulf Coast thus far are vertical, linear, and semi-continuous. Most are reasonably straight, but some bend sharply, end abruptly, or coalesce.

\section{TYPICAL ANOMALOUS FEATURES}

TEXTURE-like: Coarse-grain, poikiloblastic, friableness

INCLUSIONS: Sediments, hydrocarbons, brine, gases. Common gases are air $\left(\right.$ as $\left.\mathrm{N}_{2}\right)$, CH-compounds, $\mathrm{CO}_{2}$, and $\mathrm{H}_{2} \mathrm{~S}$.

STRUCTURES: Sheared salt, undue slabbing or jointing, voids (crystal-lined pockets), permeability, increased porosity.

COMPOSITION: High anhydrite content, visible anhydrite as grains or boudins, very black salt $=$ disseminated impurities such as clay.

A change in color (white to dark gray) is commonplace and seldom anomalous, but buff-tan colors (iron stain) may indicate brine. Layering in salt is a combination of composition, color, and structure, and is the original bedding in the salt as modified by metamorphism. Layers in the salt may emphasize other anomalous features such as impurities and shearing, but as all types of layering are commonplace, layering or lack of layering is seldom an anomalous feature.

TABLE 1 Outline of Anomalous Zones; Kupfer, 1992 
correlates with nothing else. It was also at Avery that Kupfer later suggested an anomalous zone marked by shearing and brine inflow was a possible boundary between separate salt spines [Kupfer, 1963]. That such zones were so different from the usually pure (approaching 98\%) halite led early investigators to suspect an unusual mode of origin. But Kupfer [1980] cautions that origin should be removed from the definition of anomalous zones because the same features may reflect different origins at individual domes.

The notion that diapiric salt intrusions have differential movement within the salt mass was recognized early; observations and mapping in mines showed evidence of flexural motion in the salt, fractured and slickensided surfaces, and zones of included sediments [Balk ,1949; Muehlberger, 1960; Kupfer, 1962]. Interpretations of these features suggested, among others, that these were boundaries between the zones of differential movement; various authors have offered conceptual possibilities for the origin of these features over the years [Kupfer, 1976, 1980, 1989; Howard, 1971; Talbot and Jackson, 1987]. One such description of salt motion presented the analogy of a stream of people exiting a sports stadium, wherein the overall flow was in one direction, but with rate variation within the overall stream. Another concept is that of separate "spines" within the dome having major differences in motion and properties. Recent recognition of toroidal flow in mushroom-shape diapirs in Iran [Jackson et al, 1990] has led to speculation on their occurrence elsewhere [Talbot and Jackson, 1987]. Considerable diversity exists in the conceptual models of various authors, but they all agree in the presence of the features/properties enumerated above, which have been well mapped in many mines, and suspected to occur in some solution-mined caverns. The manner of origin and the mechanics of diapiric intrusion are somewhat beyond the scope of this report; rather the properties of anomalous zones and their possible effect on solution mining is emphasized.

Kupfer [1976, 1980, 1988] distinguished between anomalous zones around the edges of salt domes and other features occurring within the salt stock. The latter features are of greatest interest to mining, as any disruption of isotropy will influence the uniformity of leaching or blasting. The shear zones described at Weeks Island and Big Hill domes are of this type, and have been termed central anomalous zones, as used by Kupfer.

Magorian believes there is often an association between external faulting and internal salt motion (shearing) and has been able to map this association at several domes, including Weeks Island [Acres, 1987], West Hackberry, Bayou Choctaw, and Big Hill (Figs. 1a, 1b, and $1 \mathrm{c})$. At Weeks Island the regional fault zones along which the Five Island salt domes 
have grown are reflected in the anomalous zone between salt spines within the dome. These shear zones also sometimes show evidence of lateral movement. The Weeks Island occurrence is further explained in the discussion of Weeks Island and on Fig. 2.

Gas outbursts and associated outburst salt in a number of Gulf coast salt mines have led to a number of serious and sometimes fatal accidents. They are apparently produced by contained gas within the salt that is released explosively and violently, usually immediately following mine blasting. They are often associated with anomalous zones; several studies have shown concentrations of methane that are 200 times greater than in normal salt [Iannacchione, 1984; Molinda, 1988]. However, zones of high methane are not necessarily associated with outbursts [Molinda, 1988]. Similar outbursts may occur in solution mining; abrupt pressure drops were noted in Bayou Choctaw Cavern 20, and saltfalls and damage to hanging strings have occurred elsewhere during leaching [Mills, 1992]. Pressure changes associated with such events suggest that gas outbursts might be involved, but are hard to prove.

In view of the large number $(\sim 1000)$ of storage caverns constructed in salt, the likelihood of individual caverns transecting multiple spine boundaries and even associated anomalous zones between spines seems very high. Instances of casing failure in caprock have occurred at a number of sites and in some may be related to underlying conditions in the salt, possibly anomalous zones. Individual cases of casing failure in caprock are attributable to other causes such as corrosion or caprock shifting, so each must be considered with respect its own features.

Most salt domes that have been studied in detail have a central graben or pair of antithetic faults which reflect the collapse of the overlying sediment and caprock with continuing upward movement of the salt. In many cases (e. g., Big Hill) this graben is centered over the anomalous zone separating the salt spines.

Mills [1992] has described numerous cases of irregular caverns, many of which were leached more than 30 years ago, at which time means of measurement were limited and the concept of anomalous zones had not been developed. Thus, it is difficult to ascribe causes to them without further investigation. However, it is believed that mineralogic and/or physical property variations are probably responsible for some of them. 


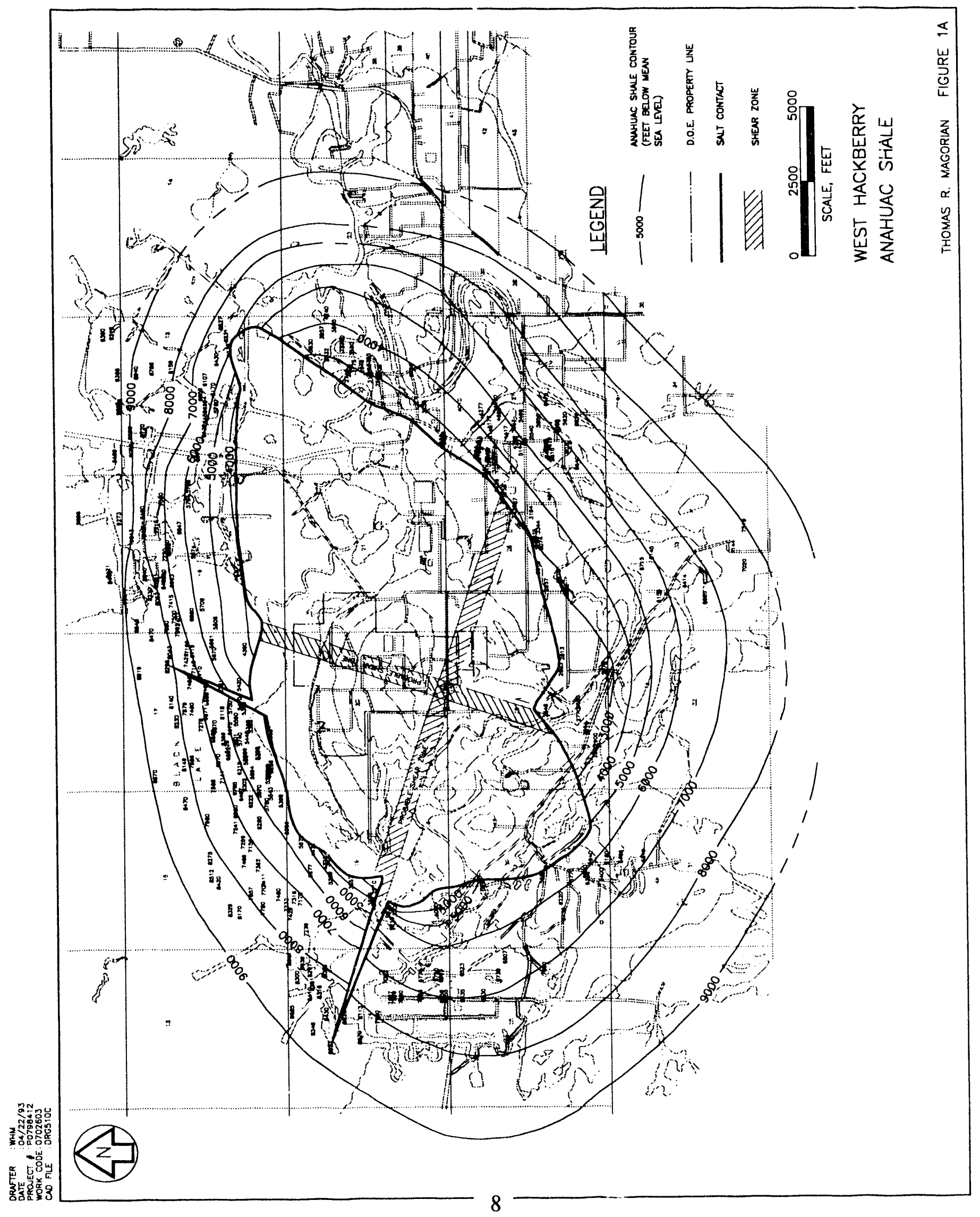




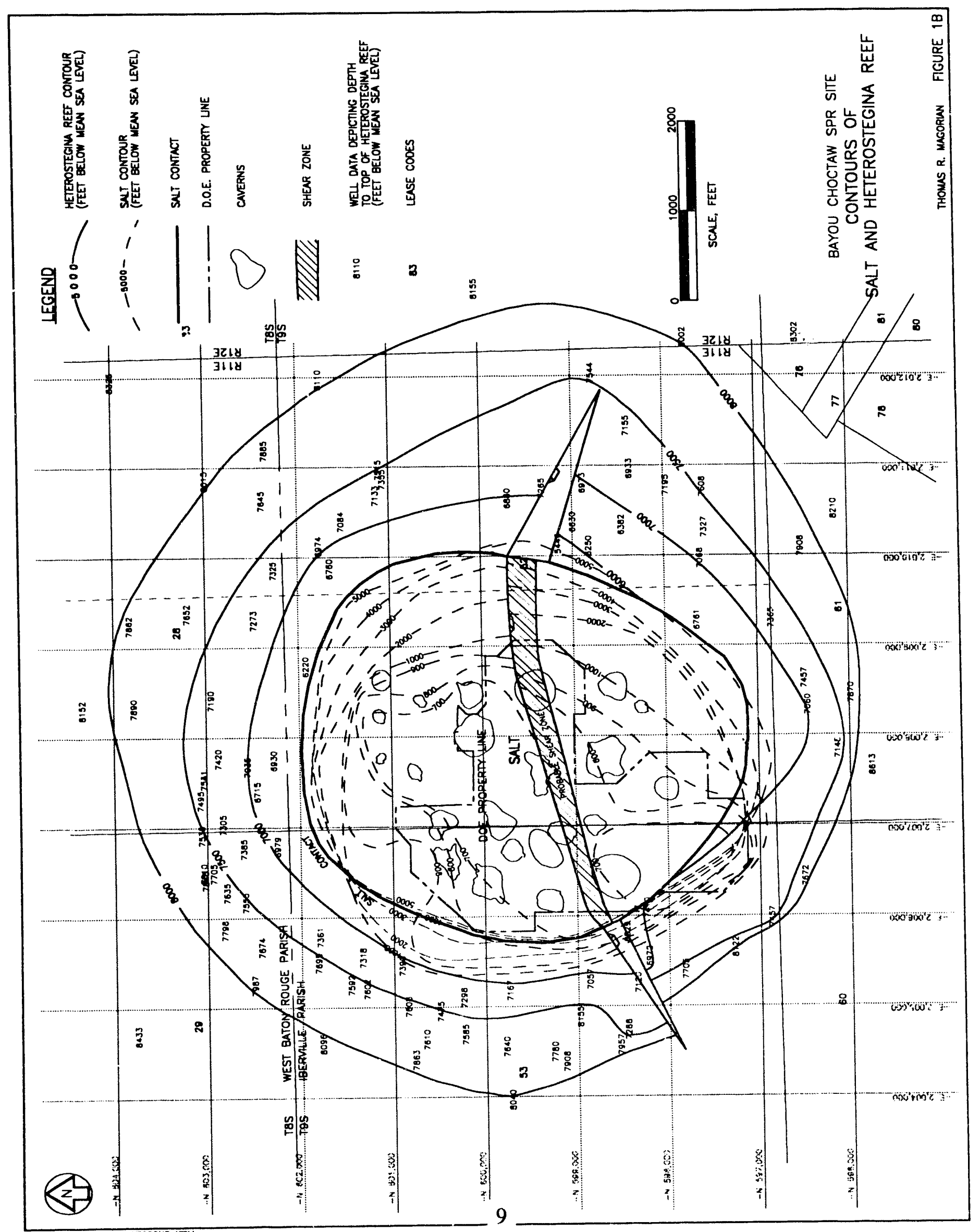




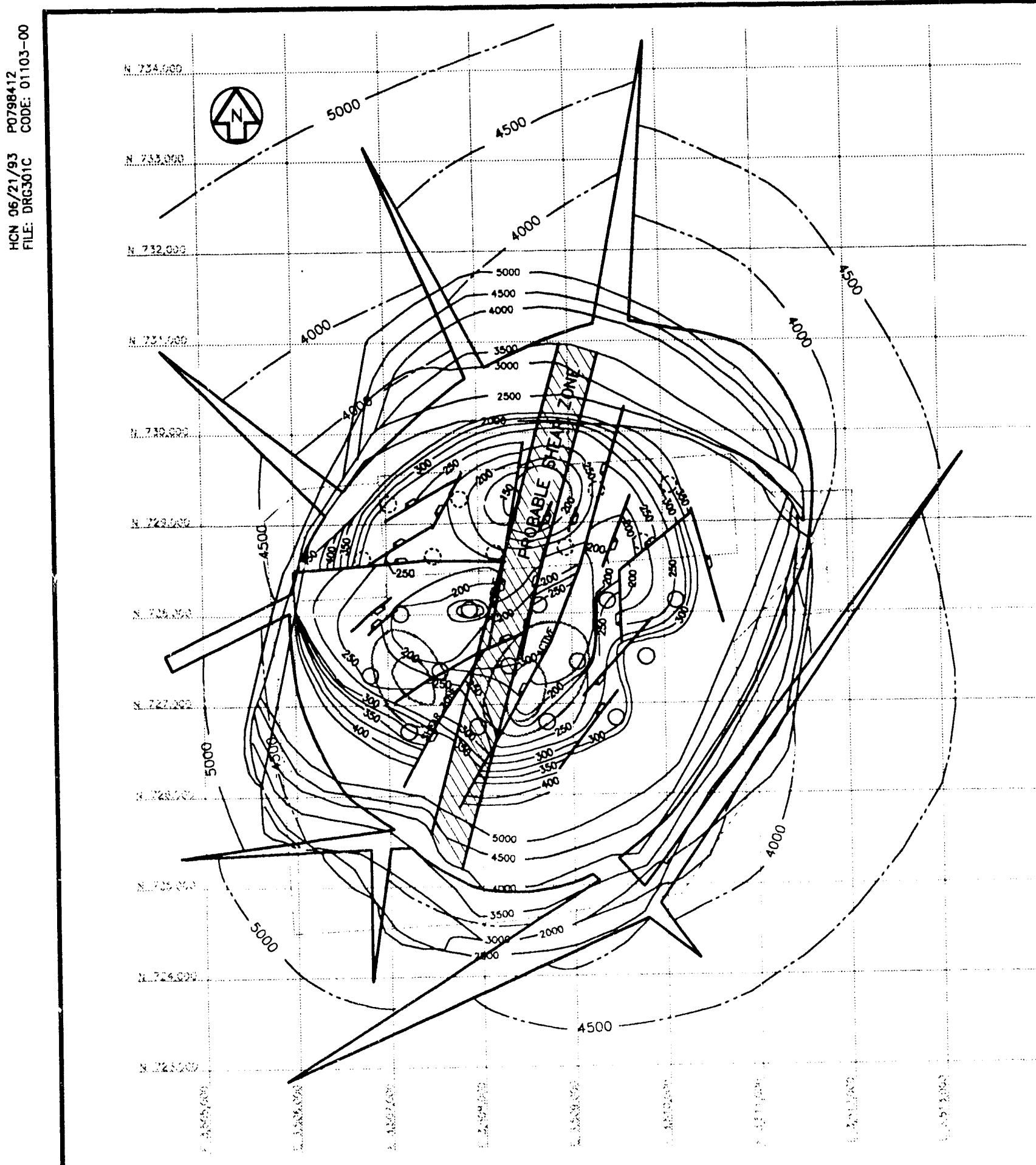

LEGEND
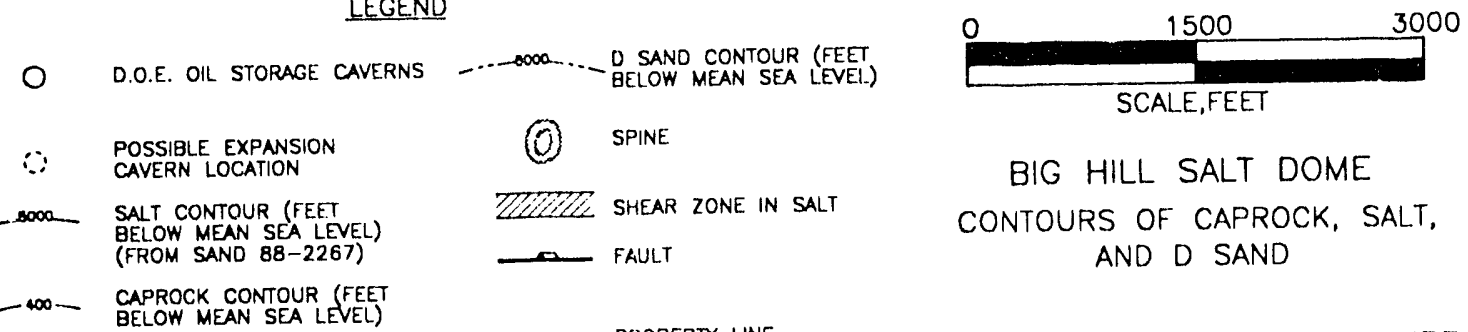

BIG HILL SALT DOME

CONTOURS OF CAPROCK, SALT, AND D SAND 


\subsection{Weeks Island, LA, Anomalous Zones}

Kupfer [1962] began mapping underground workings in the Morton Salt Company mine more than 30 years ago, and observed similar features to those seen in some Texas mines [Balk, 1949; Muehlberger, 1960]. During successive years he continued the mapping as mine development progressed. It was here and at the other domes in the Five Island group that his concept of individual spines of movement was formulated. It was also here that Magorian [Acres, 1987] saw some exterior faults correlative with interior shear zones, which separated spines of movement in the salt stock.

At least five separate shear zones have been postulated at Weeks Island and have been named A through E (Fig. 2; Acres, 1987). A brief discussion follows:

"Shear Zone A", as originally mapped, followed an alignment of gas outbursts that were encountered in both the lower DOE level $(-750 \mathrm{ft})$ and the new Morton workings $(-1200 \mathrm{ft})$. Kupfer noted this zone cut across bedding nearly at right angles in places, whereas all of the other zones are either parallel to the bedding, or else they drag the bedding into parallelism. As the new Morton mine development proceeded through this zone, blowouts, sandstone stringers, impure salt, and areas of high moisture were encountered. This zone was found by drilling to be about $150-200 \mathrm{ft}$ wide and to some extent limited the northerly extension of mining [Acres, 1987]. Magorian has postulated that a major fault (F1) with displacement at depth of more than $1000 \mathrm{ft}$ extends into the salt stock (see Fig. 3), and that this shear zone is really a manifestation of that fault, together constituting a major structure in the diapir. Kupfer (1992, personal communication) now says that he no longer believes this is an anomalous zone -- that it has been largely disproved. Kupfer does believe there are anomalous features that occur on the present northern limit of Morton's mining, and that these probably do comprise an anomalous zone.

The eastward extension of anomalous features along "Shear Zone A" could conceivably affect three or more cavern locations for an expanded SPR. The location and nature of this zone is uncertain, although some early seismic surveys conducted by Stone Petroleurn showed fault offset of about $50 \mathrm{ft}$, suggesting differential movements along adjacent spines or salt masses. Further seismic investigation is required to delineate this zone and is discussed more in a later section. 


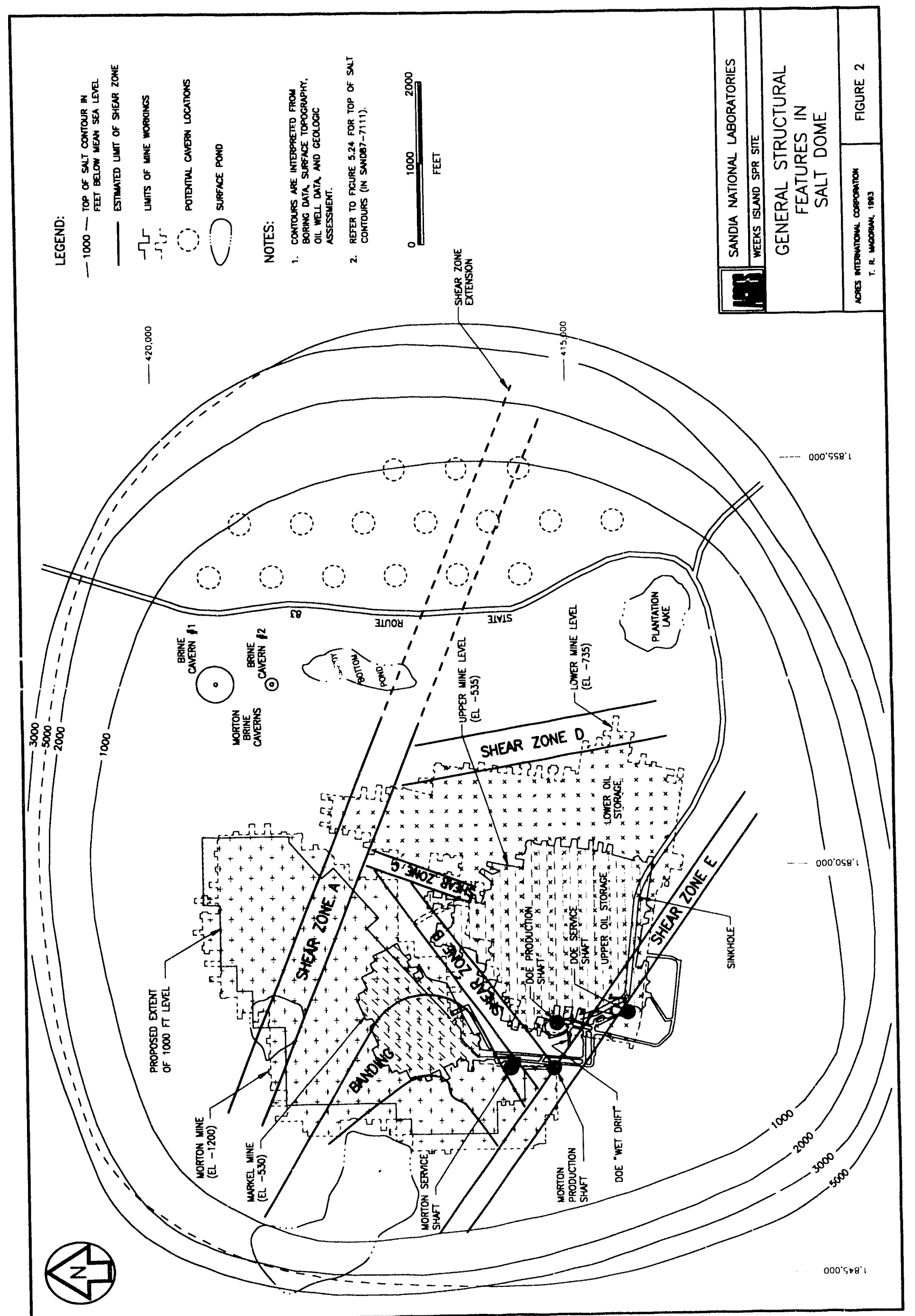

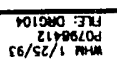




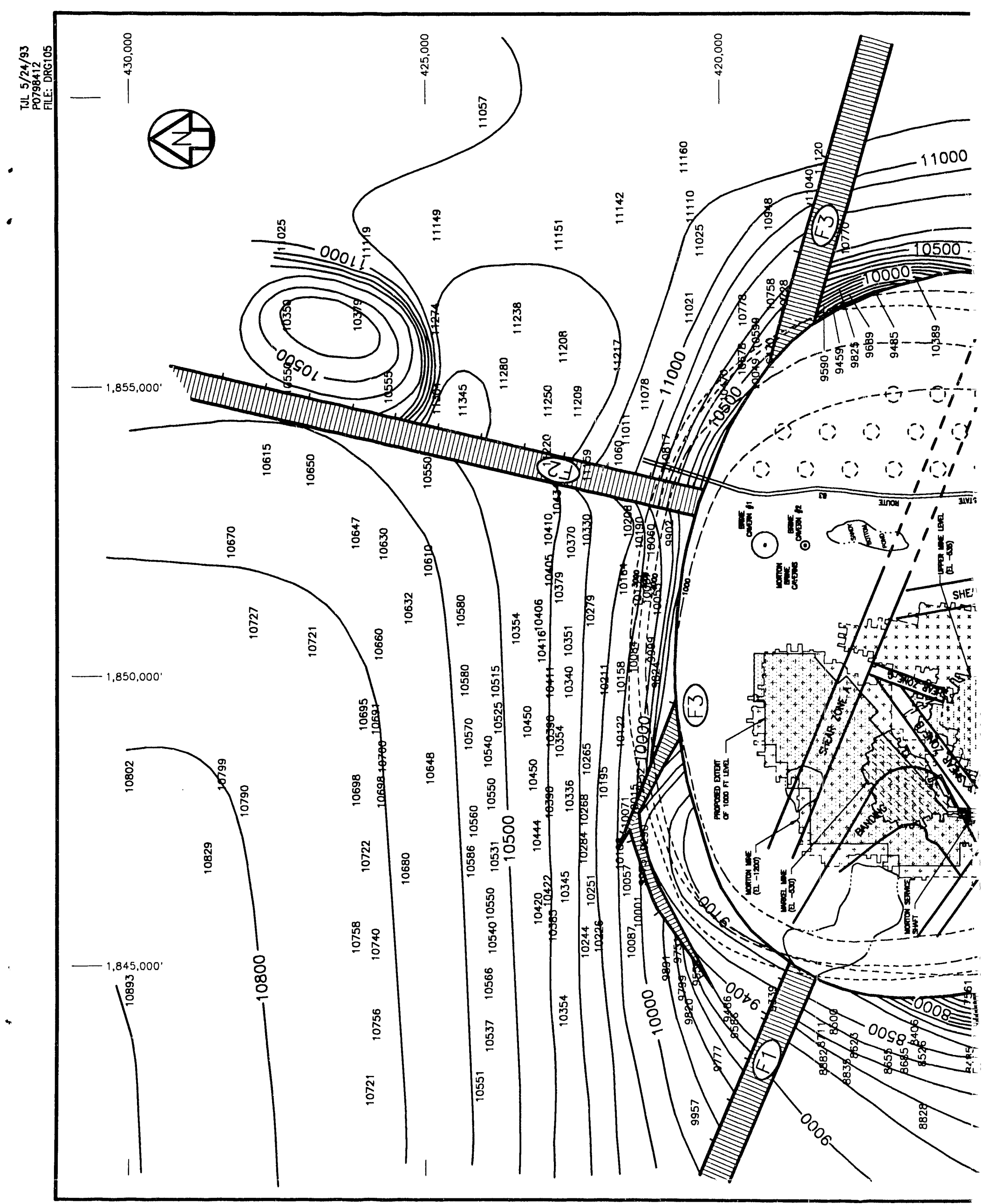




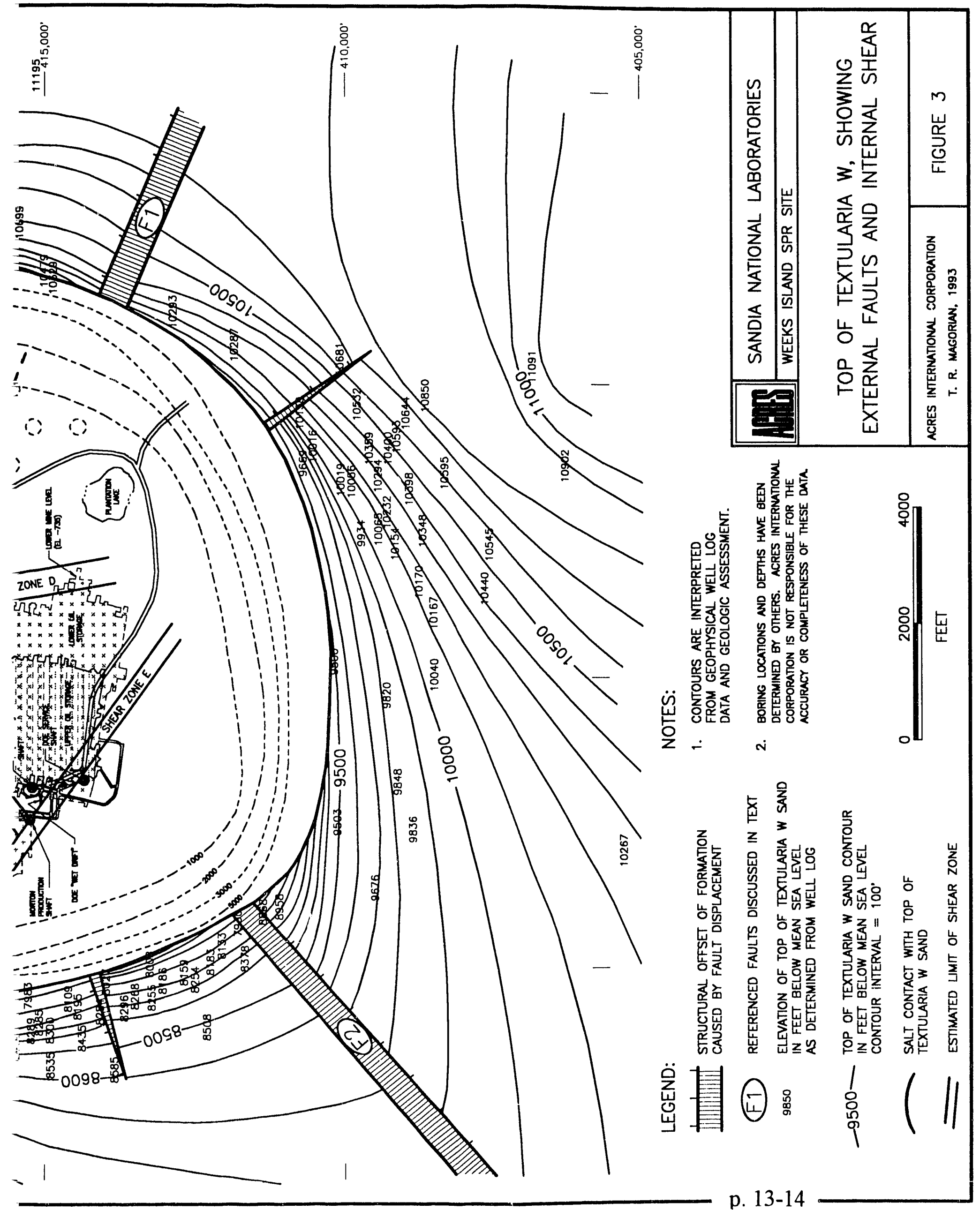


"Shear Zone B" is a structural feature of lesser proportion proposed by Magorian [Acres, 1987] and which separates the DOE oil storage from the Markel and Morton mines. Magorian indicates that mapping in the Markel drifts showed a remarkable concentration of anhydrite bands but failed to show typical shearing or the presence of sand. He further cites a pronounced valley in the top of salt and the occurrence of the "wet drift" as evidence. However, some shearing and slickensides are observed along the southern rooms in the Markel mine. Kupfer [personal communication, 1992] says his observations do not support this interpretation, indicating that the "wet drift" simply approaches the top-of-salt too closely, and that this would likely happen anywhere. He also notes that shearing is an ubiquitous feature seen in all domal salt. Thus there is lack of agreement on the definition of this zone and to what extent it is a safety hazard. It certainly is a zone of excess rigidity and there is the real problem of leakage in the "wet drift," so to be conservative it may be prudent to not seek definitional concord.

"Shear Zone C" was mapped by Kupfer on the northwestern part of the DOE lower level, dying out southward as more normal salt was encountered. This zone was characterized by numerous outbursts, liquid hydrocarbons, a sand stringer, and pegmatite-like coarse-grained salt. This zone may have been penetrated in the easternmost extent of the Morton $-1200 \mathrm{ft}$ level. This zone may also be related structurally to Shear Zone D as a secondary fold, according to Kupfer [personal communication, 1992].

"Shear Zone D" very clearly controlled the eastern extension of the DOE lower level during Morton's mining. It contained clay, sand, oil, grease, moisture, and extensive black or impure salt, and effectively precluded penetration by mining for reasons of prudence. This zone has a pronounced surface expression in the Devil's Backbone ridge to the west and the low valley and ponds to the east. Kupfer believes this zone is a boundary between two spines of salt movement, and is the major anomalous zone, extending through most of the island.

"Shear Zone E" is the southernmost zone and does not appear to be correlative with any external fault. It is marked by shearing and beds dragged subparallel to the edge of the salt stock. Gas outbursts were encountered during mining, and the top of salt appears to be irregular here. Kupfer [personal communication, 1992] believes this is only an alignment, possibly coincidental, of gas pockets and that it does not necessarily imply an anomalous zone, as by his definition three or more anomalous features are required. 
Magorian notes there is a correlation between external and internal structure at many domes he has observed (Figure 1). The association at Weeks Island is shown on Figure 3; the orientation of "Shear Zone A" is parallei to the external faulting which is controlled by the orientation of major structure in the Five Island chain of domes. Fig. 3 is a contour map of the top of the horizon marked by Textularia stapperi var. $W$ sands, which lie on a major angular unconformity and shift in spine movement according to Atwater and Forman [1959], who refer to the up side of the fault as an area of buried dome. Later drilling has shown a wide area of geopressured shale sheath here without salt. A major shift in spinal movement clearly took place here. The major anomalous zone, being vertical, coincides with the external fault dipping to the north at or just below the unconformity level. This fault runs the entire length of the Five Island chain. The Textularia $W$ or underlying Bigenerina humblei sands are believed to be the level at which sand was trapped in the anomalous zone.

The top-of-salt contours are, to a degree, also a reflection of this internal/external structure association, and which in turn is often manifested in the surface topography, as previously noted. Thus, mapping of even subtle surface features, especially linear trends, may provide clues about anomalous zones.

In May of 1992 a sinkhole was first noted along the south-central portion of the island, directly over a trough that occurs in the top-of-salt (Fig. 2). The size/volume of this feature is sufficiently large (estimated $480 \mathrm{yd}^{3}$ ) that the possible correlation of its occurrence over the salt trough, or its association with an anomalous zone ought to be questioned. It is simply too large to be caused by any surficial processes, thus an answer in other subsurface features is sought, especially voids created by the dissolutioning of salt. Subsurface exploratory drilling around the DOE service shaft in 1986 identified the presence of irregularities and saturated void space along the top of salt; such features, if present under the sink hole, could account for collapse of the surface into such voids. Effectively, such a process describes salt karst development, although the term karst typically is used in limestone terrain. More widespread salt karst is seen over the Supai salt basin south of Holbrook, AZ, and in other locations. An alternate explanation is that water has been leaking into the mine and dissolving salt in the process, which in turn creates void space into which overlying sediment can slump. Until further study or data becomes available, the cause of this feature will of necessity remain speculative. 


\subsection{Big Hill, TX, Anomalous Zones}

Magorian mapped what he believed to be separate spines in the salt stock at Big Hill, based on correlation of anhydrite banding observed on geophysical logs [Magorian and Neal, 1988]. Such mapping had not been accomplished anywhere before, principally because the data from closely spaced grids necessary to make the interpretation were not available. He further mapped a shear zone between the two spines, based on observed vertical displacement in the caprock. The available geological evidence supports the notion that this is a manifestation of an anomalous zone. Kupfer [1988] cautions that separate spines in a dome do not necessarily have anomalous features or zones between them. Thus multiple evidence from several anomalous features is necessary.

At Big Hill one idiosyncrasy has already been identified during the leaching of Cavern 114 , which is located just west of the postulated shear zone crossing the dome, and along the southwest edge of the dome (see Fig. 1c). Both gaseous and liquid hydrocarbon condensates were encountered during the sump leaching stage of cavern development [Mills, 1992]. Some 150 barrels were produced and analyzed and other tests were performed to isolate the source of the hydrocarbons. No leaks in the casing were identified and leaching continued, whereupon little additional production ensued. The hydrocarbons were thought to have occurred in an isolated pocket, but their possible occurrence in association with an anomalous zone, especially near the dome edge, must be considered. Magorian believes the occurrence of hydrocarbons is not coincidental, and that the locution adjacent to the south overhang may exacerbate the migration of hydrocarbons into the salt.

Cavern 103, also located astride the postulated anomalous zone, experienced excessive corrosion during sump development and this was attributed to highly alkaline brine. Whether this is a feature of the anomalous zone here is unknown, but Kupfer [personal communication, 1992] reports concentrations of alkaline brine along anomalous zones at Cote Blanche and Avery Island, LA. Also, at Jefferson Island a $\mathrm{CaCl}_{2}$ brine was reported to have flowed for a week or so.

Cavern 109, also located astride the postulated anomalous zone, developed unusual behavior during leaching, and when depressured during workover, produced more gas than usual and maintained a 2 -inch brine stream as a result of the pressure buildup. 
Few other problems were encountered during cavern development and it is not known if the anomalous zone was penetrated in any other caverns.

However, the northward extension of the postulated shear zone extends close to areas potentially available for new caverns (Fig. 5). The character of this shear zone as determined from seismic surveys, and the implications associated with construction of caverns are discussed in Section 4 of this report.

\section{SURFACE INVESTIGATIONS}

Previous investigations at several locations have shown that structural features in salt stocks are often manifested in geomorphic expression at the surface. That is, differential motion in the salt mass can result in surface expression in the form of ridges, ponds, or depressions, any of which can occur in linear or arcuate form. Erosion may reduce these features to low relief, possibly only a few meters; thus their recognition may require specialized studies, such as soil geomorphic texture/structure mapping.

\subsection{Avery and Jefferson Islands}

At Avery Island Kupfer [1963, 1974, 1976] mapped a boundary shear zone within the underground mine levels, which he believed separated two spines of salt; he also described geomorphic evidence for its surface expression. Autin et al. [1986] cited several lines of evidence for this also, based on a study of surface soils. They noted that the overwash colluvium on the southeastern side of the island is about $1000 \mathrm{ft}$ wide, whereas the northwestern side averages about $500 \mathrm{ft}$. Secondly, he showed the southeastern side is more dissected than the northwestern side. Thirdly, they saw a larger and possibly older set of ponds on the southeastern side. They also observed two conjugate shear joint sets in a sand pit with modal orientations indicating an extension direction of about $\mathrm{N} 12^{\circ} \mathrm{E}$, essentially parallel to the trend shown by the underlying shear zone northeast of the pit.

At Jefferson Island, just northwest of Avery Island, Lake Peigneur atop the dome suddenly drained into the salt mine below, following accidental penetration of the mine by a drilling rig on 20 Nov 1980. This event prompted numerous investigations that looked at safety, geological, and environmental questions. Autin [1984] saw the process as being somewhat analogous (but on a much different time scale) to natural subsidence processes that occur over many domes along the Gulf Coast. Although there is lack of agreement on the 
presence of spines at Jefferson Island and their involvement in the mine flooding, some believe that anomalous zones exist and have contributed to previous unstable conditions. The presence of shear zones has been shown to contribute to the surface ridge and adjacent depression and ponds at Weeks Island.

\subsection{Weeks Island Investigations (Louisiana Geological Survey)}

Shallow core examinations of surficial sediments were undertaken, similar to those investigations at Avery Island and elsewhere. Several traverses across the entire island were planned, but permitting constraints resulted in incomplete survey lines and less data obtained than initially desired. Some 16 shallow boreholes (19-35 ft depth) were completed and have provided useful information about ongoing pedologic processes and landscape evolution history. Cores were described in the field using a qualitative sedimentologic/pedologic procedure modified from methods used by soil scientists. The detailed logs and results are described in Autin and McCulloh [1993].

The present topography at Weeks Island is a reflection of the diapiric rise of the salt mass, including differential structural motion of the salt mass and its gradual dissolution in overlying saturated sediments, and differential erosion of the overlying sediments and stratigraphic units. The highest position on the island is associated with the "Devils Backbone," named by previous investigators [Acres, 1987]. An intermediate elevation landform component, the Middle Salt Island, occurs between the High Salt Island (manifested in the Devils Backbone) and the Low Salt Island. The surficial stratigraphic soil units are represented by the Peoria Loess and associated mixing zone which overlies a regional alluvial unit, the Mt. Pleasant Bluff Alloformation (Fig. 4) of the Prairie Complex, a late Pleistocene deposit of the Mississippi River. The sequence at Weeks Island of sand and gravel grading upward into loams and sandy loams with a paleosol at the top indicates a probable meander belt depositional environment. In contrast, the laminated clays at Cote Blanche with few silty and sandy interbeds grading upward into a clayey paleosol, indicates a likely backswamp depositional environment.

That these units have been elevated some 50 meters (164 ft) since late Wisconsinan times (within the last 25,000 yrs) demonstrates the active rise of the salt mass. The boundary of these landform/topographic components with the High Salt Island may in part coincide with internal shear zones within the salt [Kupfer, 1976; Acres, 1987], as noted earlier in this report. 
HORIZONTAL DISTANCE (mełers)

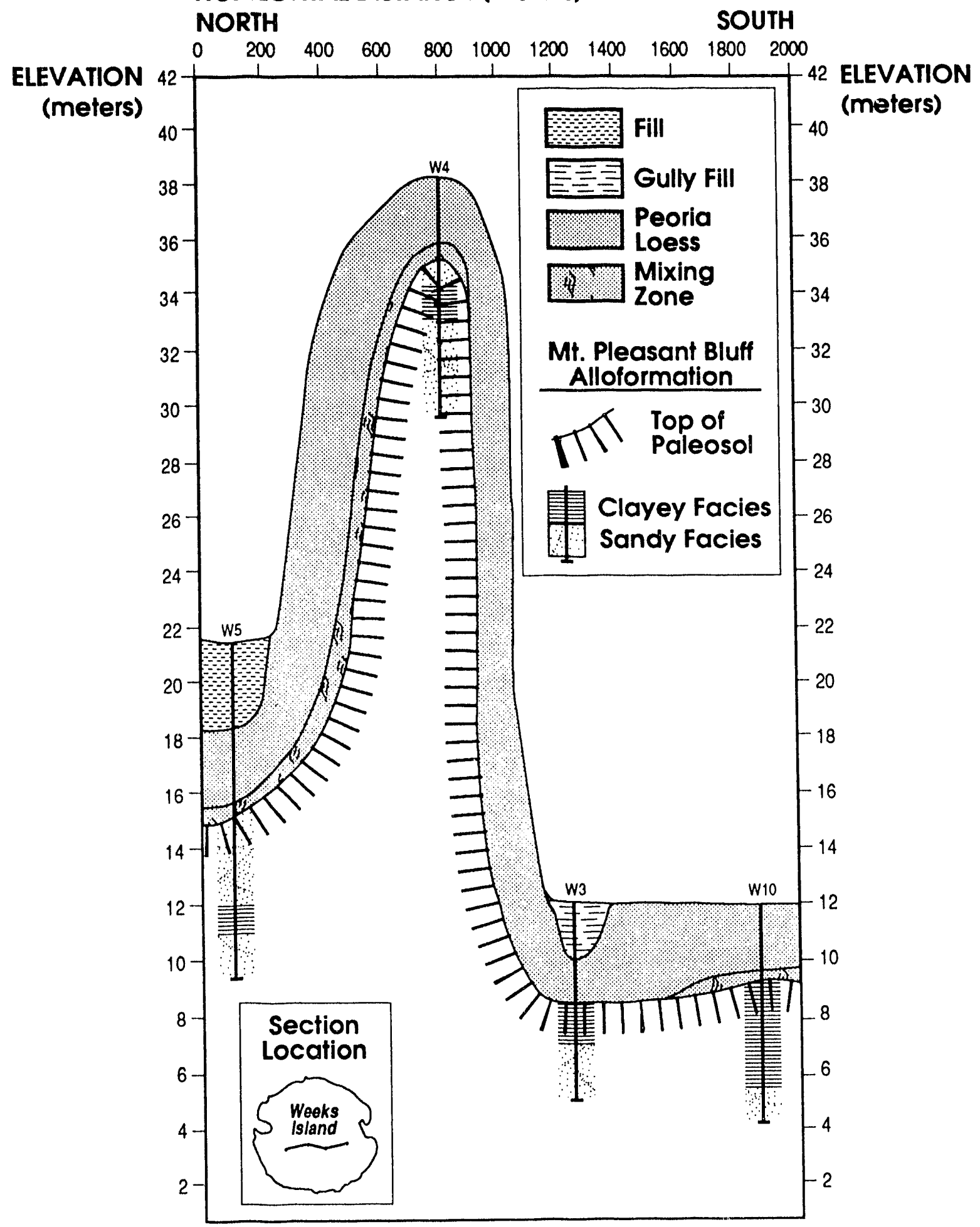

Figure 4 Association of Surficial Sediments Across Devil's Backbone, Weeks Island 
No shear fractures or faults in the surface sediment at Weeks Island have been described in the literature, possibly because the sandier sediments mask recognition of such features. Surface faulting is not as evident at Weeks as at Avery and Cote Blanche Islands because of the coarser sediments and greater uplift rate, which has removed more of the evidence. Although the Mt. Pleasant sediments are generally sandy clay loam to sand, some clayey units were identified along the southern part of the transect along LA Highway 83, east of the area with previously defined or inferred shear zones, and these contained shear fractures, or possible shear fractures. However, the distribution of observed fractures in this location, or any other at Weeks Island, shows no conclusive relation to potential surface lineaments in the topography. In contrast, conjugate shear fractures were observed in Red Bluff at Cote Blanche Island, and although these showed no displacement, other small faults are visible and do reveal measurable displacement estimated at several centimeters that may be related to tectonic structure, or to movement in the salt mass.

The lack of conclusive results at Weeks Island that would relate surface soil features to anomalous zones in the salt mass is likely a reflection of the limited access and small number of samples. There is much that can be learned by further surface examination of outcrops in the high-relief areas of the island and in closely spaced borings elsewhere. Additional surface mapping is being pursued and will be reported on by Autin and McCulloh [1993]. Highresolution seismic surveys can find valleys in the top of salt as well as active faults. Traverse lines off the dome and VSP (vertical seismic profiles) or salt proximity surveys from well bores are needed to define overhangs at the intersections of anomalous zones or regional faults.

\section{SEISMIC INVESTIGATIONS}

\section{Introduction}

Seismic reflection profiling over salt domes has been a primary geophysical tool for developing oil and gas prospects, as it is able to image the deep flanks of domal structure where hydrocarbon traps occur. In recent years the advent of improved instruments, sensors, and processing has enabled a much improved level of detail to be obtained at more shallow depth and with greater precision. These newer high-resolution methods were employed at the Big Hill, TX, salt dome in an attempt to obtain further understanding of the internal dome structure and anomalous features there (Chapter 2, this report). Weeks Island was to have been included in the study, but permission to profile the island could not be obtained. 


\subsection{Big Hill Seismic Studies}

This Section by T. R. Magorian, R. S. Harding, Jr., and C. Walker, Jr.

The method used at Big Hill employs a compressed-air energy source (10 in ${ }^{3}$ Bolt air gun) having similar dynamic frequency response as explosive sources, but superior safety and environmental features and consequently more versatile operational capability. The seismic receivers are hydrophones, loaded down shallow boreholes 10 feet or more below the water table. This receiver environment reduces much of the surface noise effects from wind and machinery, and is below the aerated near-surface sediments that absorb the higher frequencies of seismic energy $(>\sim 100 \mathrm{~Hz})$.

The four principal traverse lines at Big Hill trended nearly east-west and were about a mile in length, with tie-lines through the center and along the west side of the DOE property (Fig. 5). Shotholes were placed on $25 \mathrm{ft}$ centers, and hydrophone receivers were placed in every hole and connected to the seismograph through a multi-conductor cable. The air gun was then fired by radio in every hole, after first pulling the hydrophone and checking for noise and continuity. After the data was recorded the instrument observer would instruct the shothole crew to proceed to the next station and repeat the procedure. The data aquisition process is labor-intensive and the entire survey required several months to complete.

The seismic data was digitally recorded on magnetic tape, and pertinent information from the observer's field acquisition logs was transcribed to a spreadsheet to set up the processing sorting and sequencing. The data on tape were demultiplexed, shot and receiver statics were applied, and spherical divergence gain corrections were made.

The processing flow included spiking deconvolution with a 60 millisecond operator, followed by stacking velocity analyses using both constant velocity stacks and semblance velocity spectra spaced at every 10 shotpoints. After applying zero-dip normal moveout (NMO) corrections, dip moveout (DMO) was applied to constant offset sections, followed by reverse-NMO and a second iteration of velocity spectra, from which final stacking velocities were picked. Final NMO corrections were then applied to the DMO-corrected data. Automatic residual statics were computed from the NMO-corrected common midpoint (CMP) gathers and applied to the CMP gather traces.

At this stage of the data processing some experimentation with limited offset stacks was performed on CMP gathers at the edge of the salt. The salt edge reflection images were 
found to be highly serisitive to the range of offsets included in the stacked traces. This indicates rapid lateral velocity change between the caprock (estimated at $15-18 \mathrm{kft} / \mathrm{sec}$ ) and the surrounding clastic sedirnent $(5.5 \mathrm{kft} / \mathrm{sec})$, which occurs over a distance of significantly less than one seismic spreadlength. Imaging of reflections using CMP stacking techniques has distinct limitations under these circumstances. Pre-stack migration could potentially be benefit imaging the salt flanks, but detailed knowledge of the 2-dimensional velocity structure is generally required for this approach to be advantageous. The lack of reliable sonic log data, or other velocity survey data, from the SPR caverns at Big Hill impedes using to advanced imaging techniques, which could be applied to mapping the salt flanks.

The CMP stacks were migrated using smoothed post-DMO stacking velocities and $\dot{i}$ wave equation migration algorithm. Final display filters were applied to both the CMP stack and migrated sections.

\section{Interpretation of Data:}

The high resolution survey allowed the identification of many minor faults that were previously unknown (see Figs. 6.18), in addition to the major structure that had been mapped. Several of these form either grabens or stepped faults en echelon. The fine stratigraphic control over the caprock even indicates which of them are still active.

The reflections from the caprock atop the dome are the clearest on the seismic records. An unmigrated time map was made on it which shows the overall domal form as known, but in less detail (and only on the SPR acreage) from that obtainable from well control. It ties to the subsurface data quite accurately, with a velocity slightly more than $6000 \mathrm{ft} / \mathrm{sec}$, as would be expected in the limy sands found above the caprock.

\section{Shallow Stratigraphy:}

The Beaumont clay was deposited since the Holocene rise in sea level, only on the flanks of the dome, uplifted only a few feet and still subject to storm flood sedimentation. It lies on Montgomery sand (or Prairie complex) overlying the caprock on the dome. These beds are correlated with lower Beaumont B and C (Autin, personal communication, 1992). The prominent seismic marker at 180 milliseconds on Line 5 and the ends of the other lines across the dome is considered upper Lissie, based on correlation with the Sunset and other wells with shallow electric logs. Autin considers this sand basal Montgomery. 


\section{Active Faults:}

The dome is broken by a central graben trending NNE-SSW and which includes Caverns 103, 108, and 113 (Fig. 5). This central graben is crossed by all four lines and its bounding faults are clearly the largest on all but Line 2 . The faults on both sides of this graben are active, as indicated by displacement of all of the observable reflections to the surface, and by surface topographic features that can reasonably be interpreted as fault scarps. These faults converge with depth, meeting at the known top of the salt, along with the anomalous zone characterized by anhydrite bands within the salt, as mapped by Magorian and Neal [1988]. The west fault was mapped from caprock depths during drilling of the cavern wells. It could not be seen in the widely-spaced sulphur exploration holes or the regional seismic lines whose data is shown only below 100 milliseconds, the only data available prior to SPR development. By knowing the alignment of caprock faults before cavern development on the Sabine Pass Terminal property, the high-resolution seismic survey avoids a number of drilling problems which could lead to much greater excess cost and potential threats to cavern integrity.

\section{Other Caprock Faults}

Another major fault runs almost east-west just south of the intersection of lines 2 and the tie line across the dome (Figs. 5, 18). The antithetic fault related to this forms the short $\mathrm{ENE} / \mathrm{SSW}$-trending graben, and the valley at the surface. Its depth is uncertain because the energy coming from the bottom may be entirely diffractions off the faults, particularly at the top of the massive anhydrite. While this fault may represent an anomalous zone wirich divides the dome into four spines [Walker, 1992], it is tied to the external fault found in the overhang in the Amoco 11 dry hole and mapped along the northwest side of the dome by Dollison [1965], possibly pait of the same master fault system. As a result, only two spines are indicated in this part of the dome, with the possibility of a third and even a fourth on the Sabine Pass Terminal Property. The dominant regional fault pattern discussed below and all the additional minor faults that were found indicate two spines. The dome is half the size of Weeks İsland, known for its four spines. 


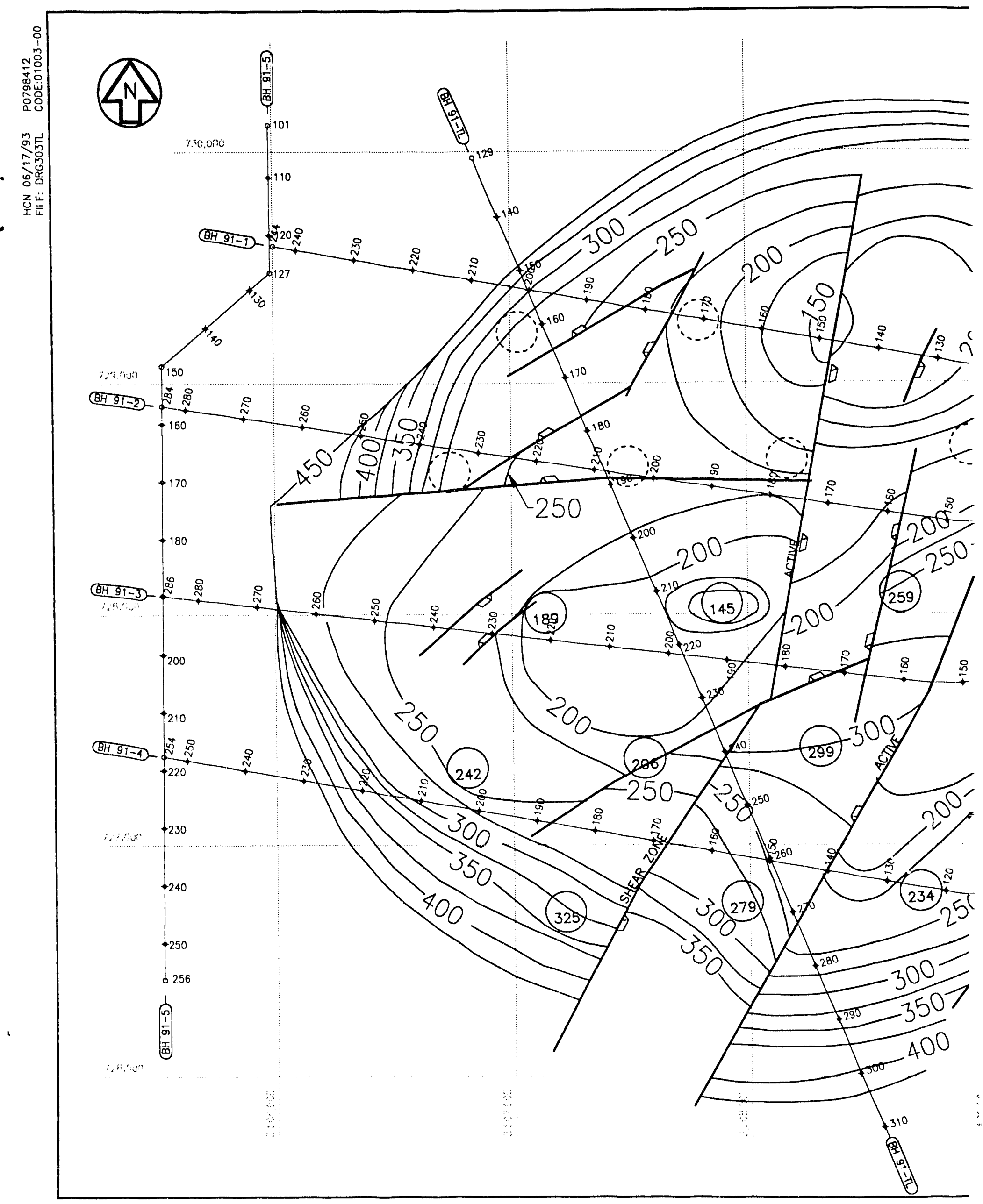




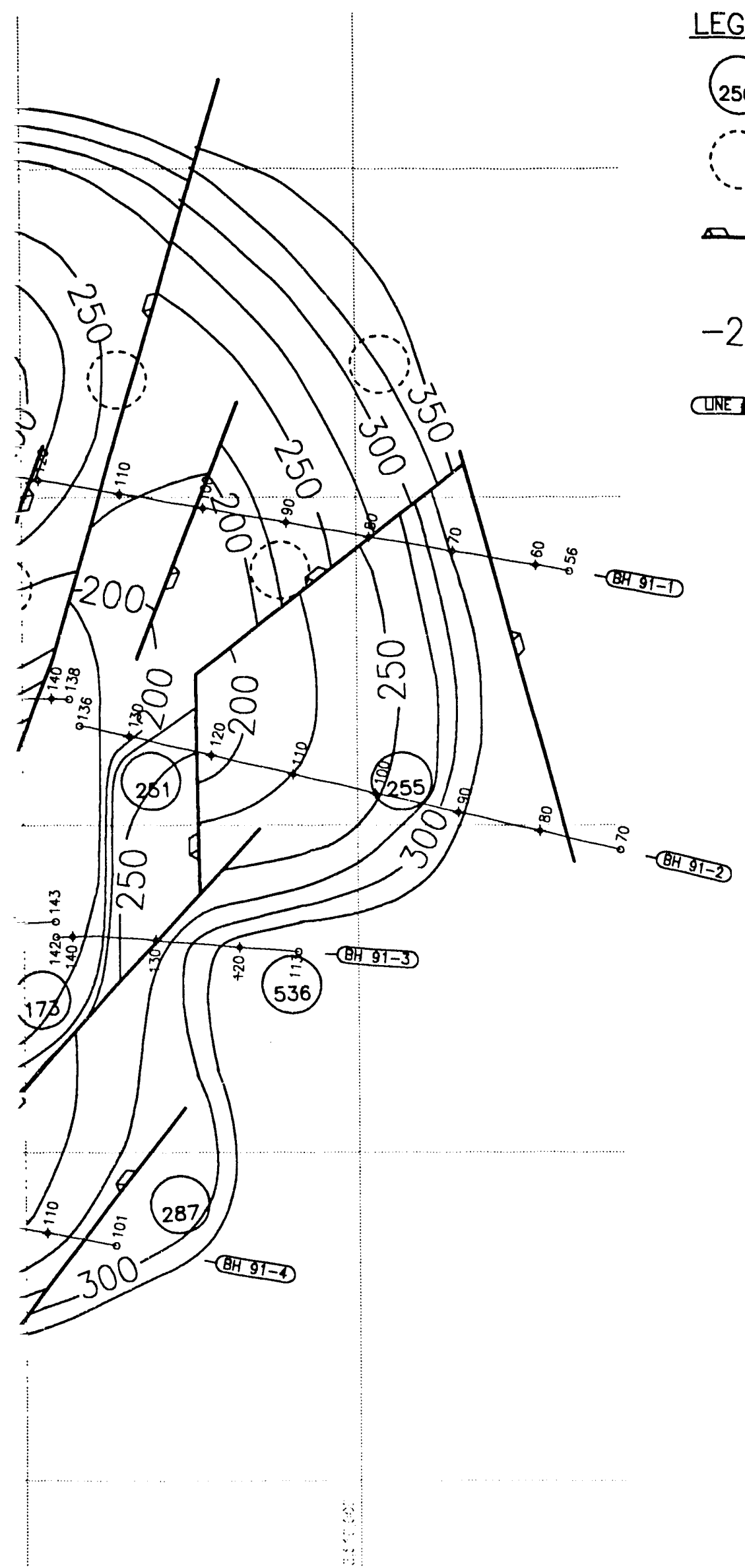

LEGEND 250 D.O.E. OIL STORAGE CAVERNS SHOWING
DEPTH TO CAPROCK IN FT

POSSIBLE EXPANSION CAVERN LOCATION

FAULT

-250- DEPTH CONTOURS BELOW SEA LEVEL IN FT, SEISMIC LINES DELINEATING SURFACE STATIONS

AVERAGE VELOCITY TO CAPROCK $5000 \mathrm{FT} / \mathrm{SEC}$

\section{BIG HILL SPR SITE CAPROCK \\ MIGRATED SEISMIC MAP \\ 25 FOOT CONTOUR INTERVAL \\ $0 \quad 500$ 1000 \\ SCALE, FEET}


NOTE: Figures 7-18 on pages 28-39 are reduced to the smallest scale that is practical for easy viewing and comparison of migrated and stacked sections (with interpretations shown). Anyone requiring the full 11" $\times 17^{\prime \prime}$ format may request them from the first author (Neal).
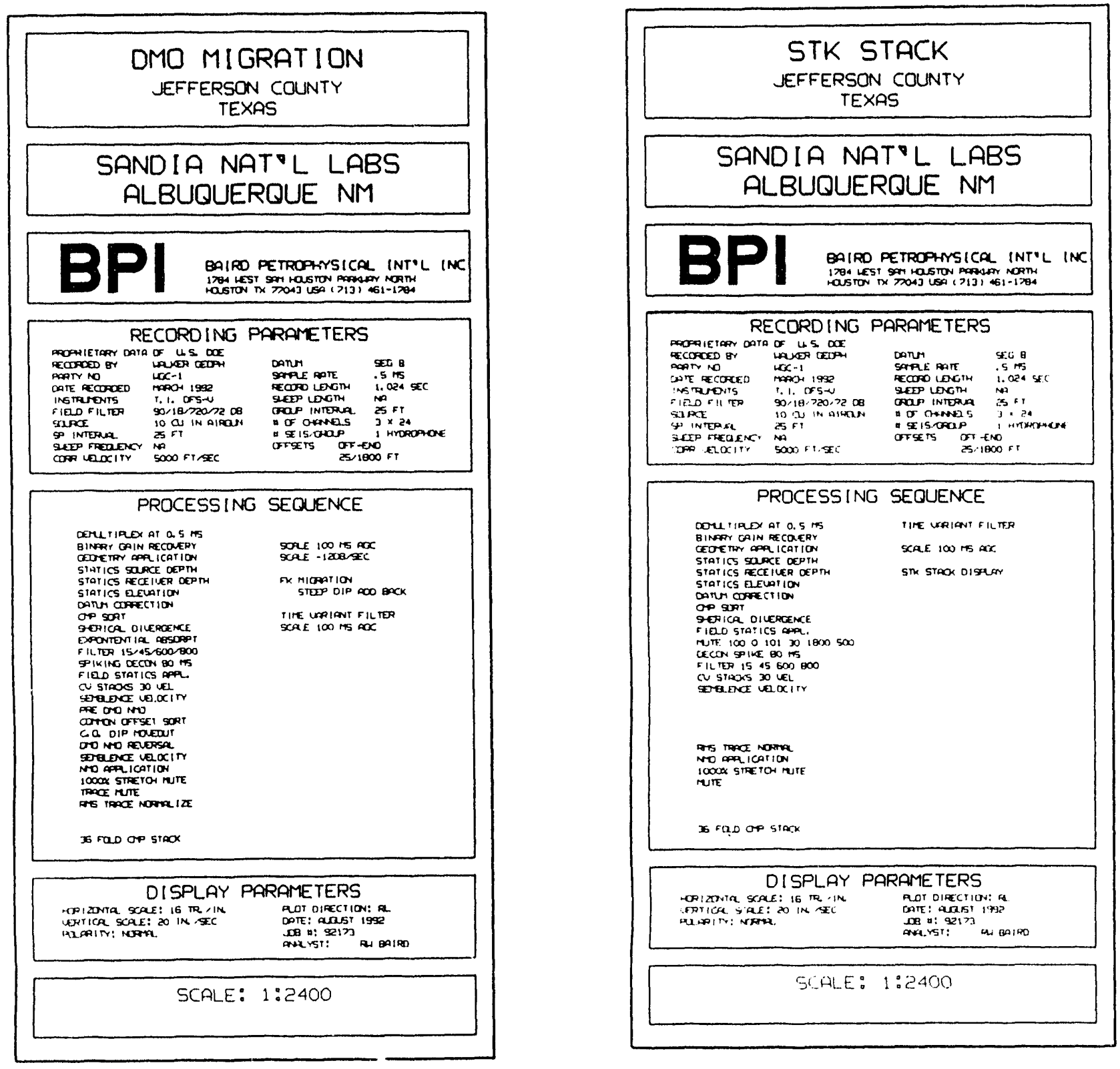

Figure 6 Recording and Display Parameters for Seismic Profiles, Figs. 7-18, pages 28-39. 


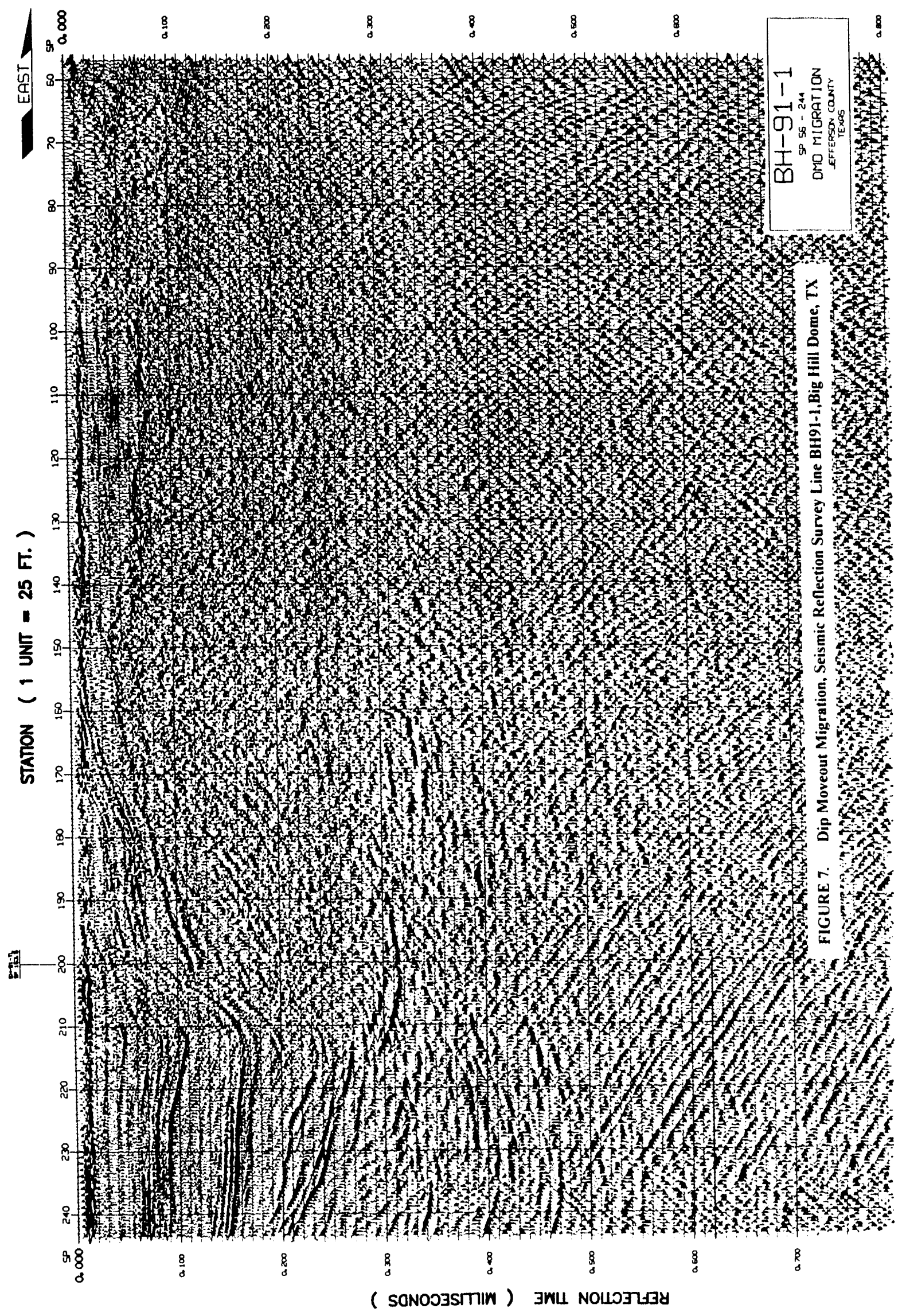




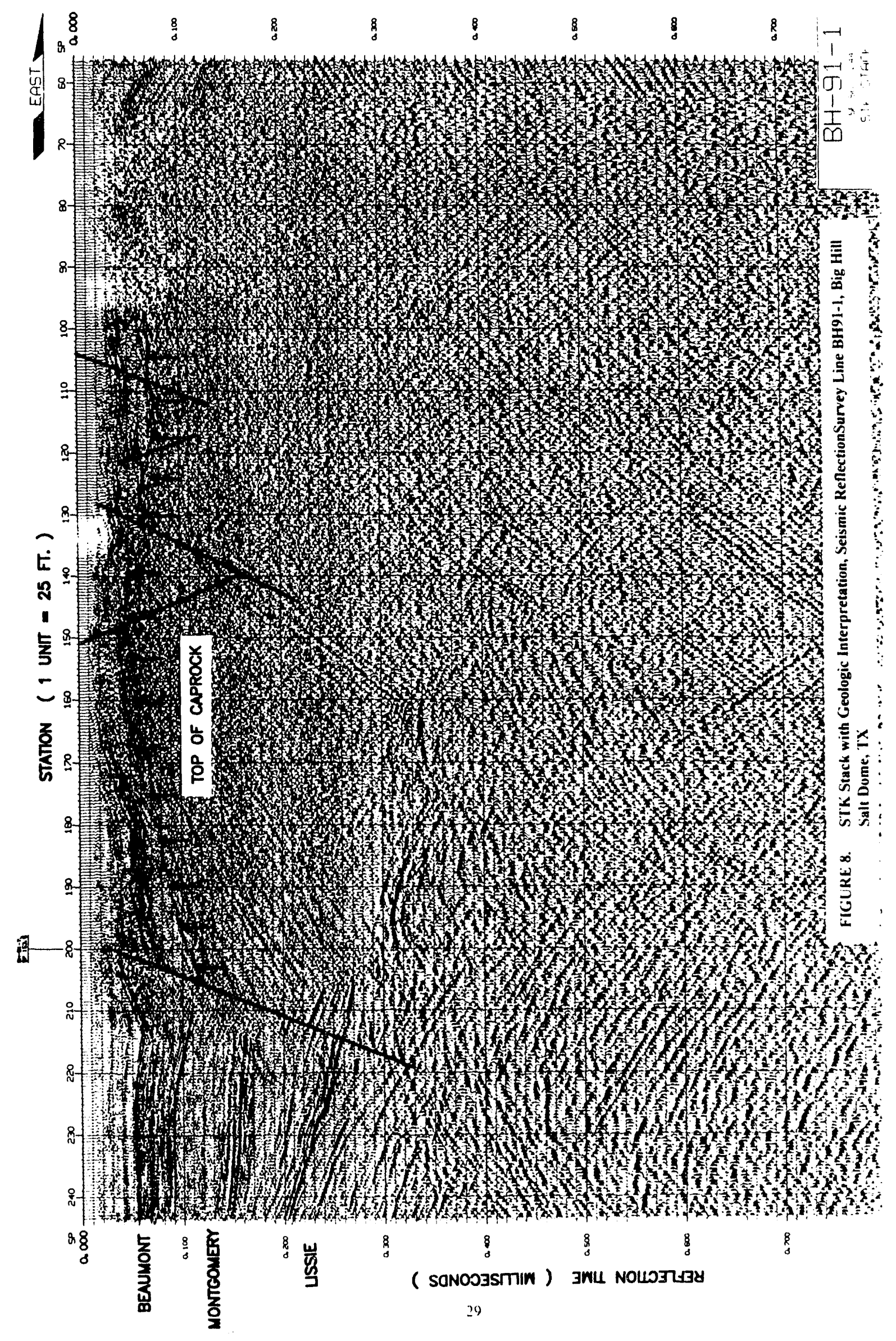




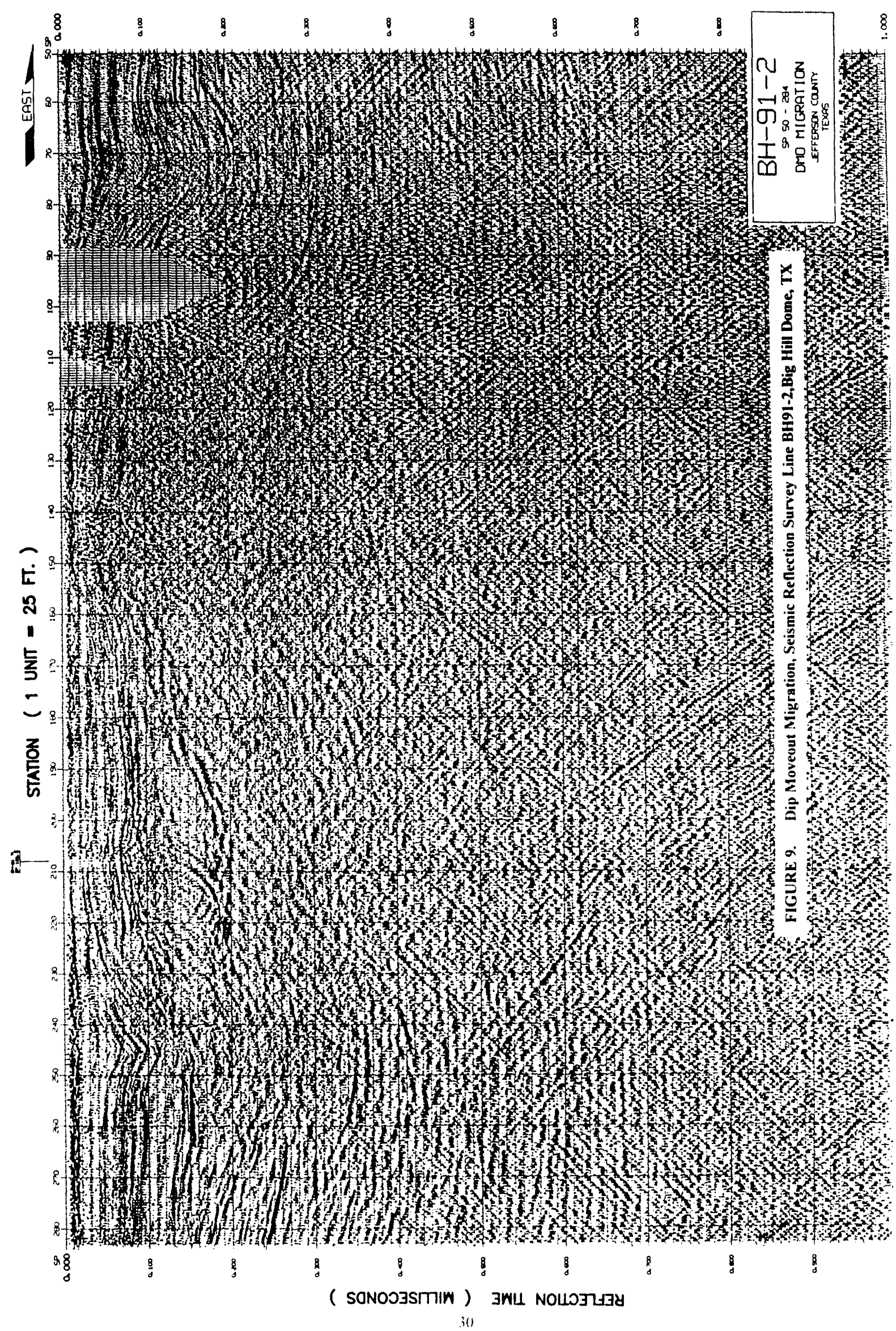




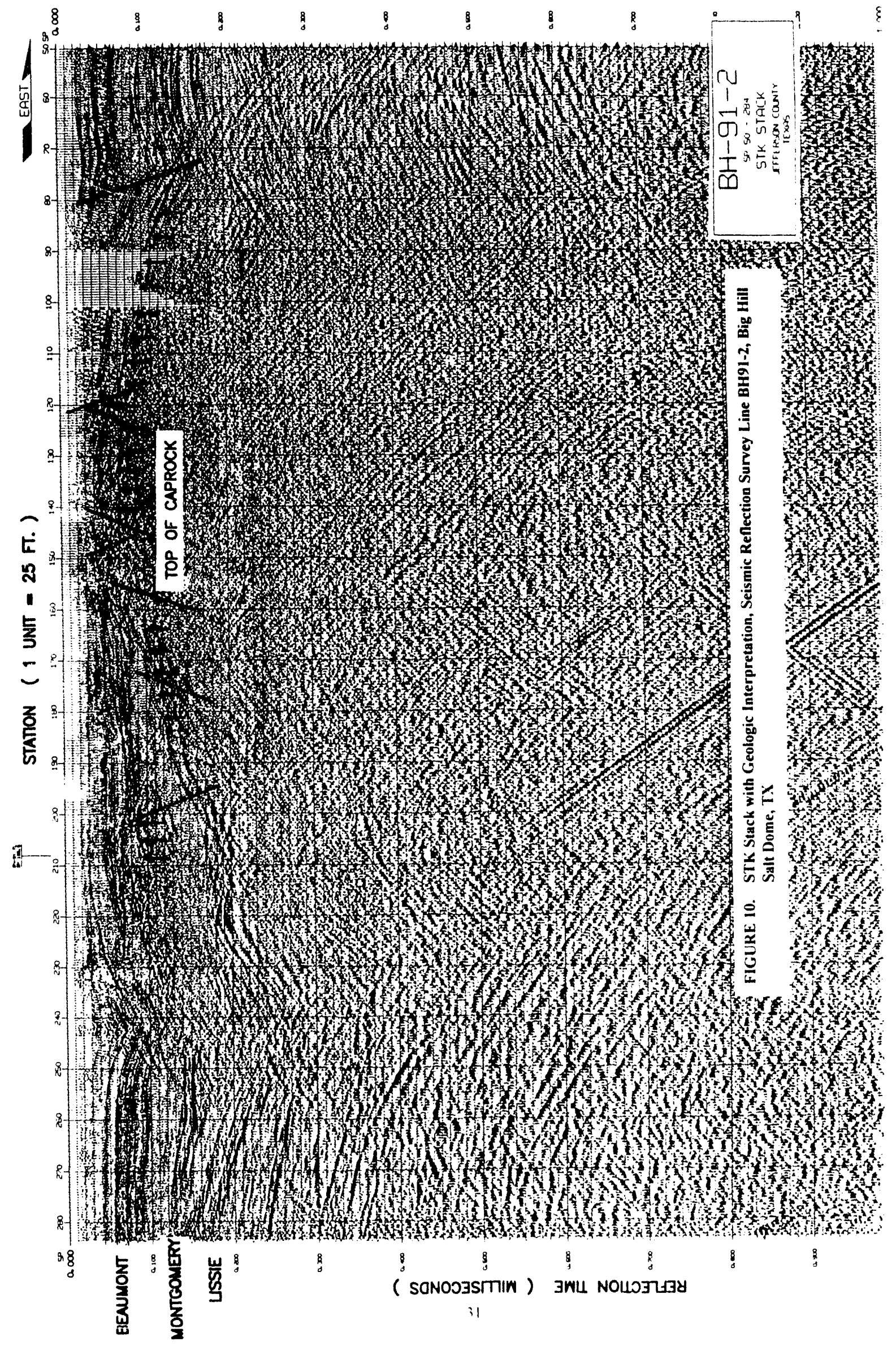




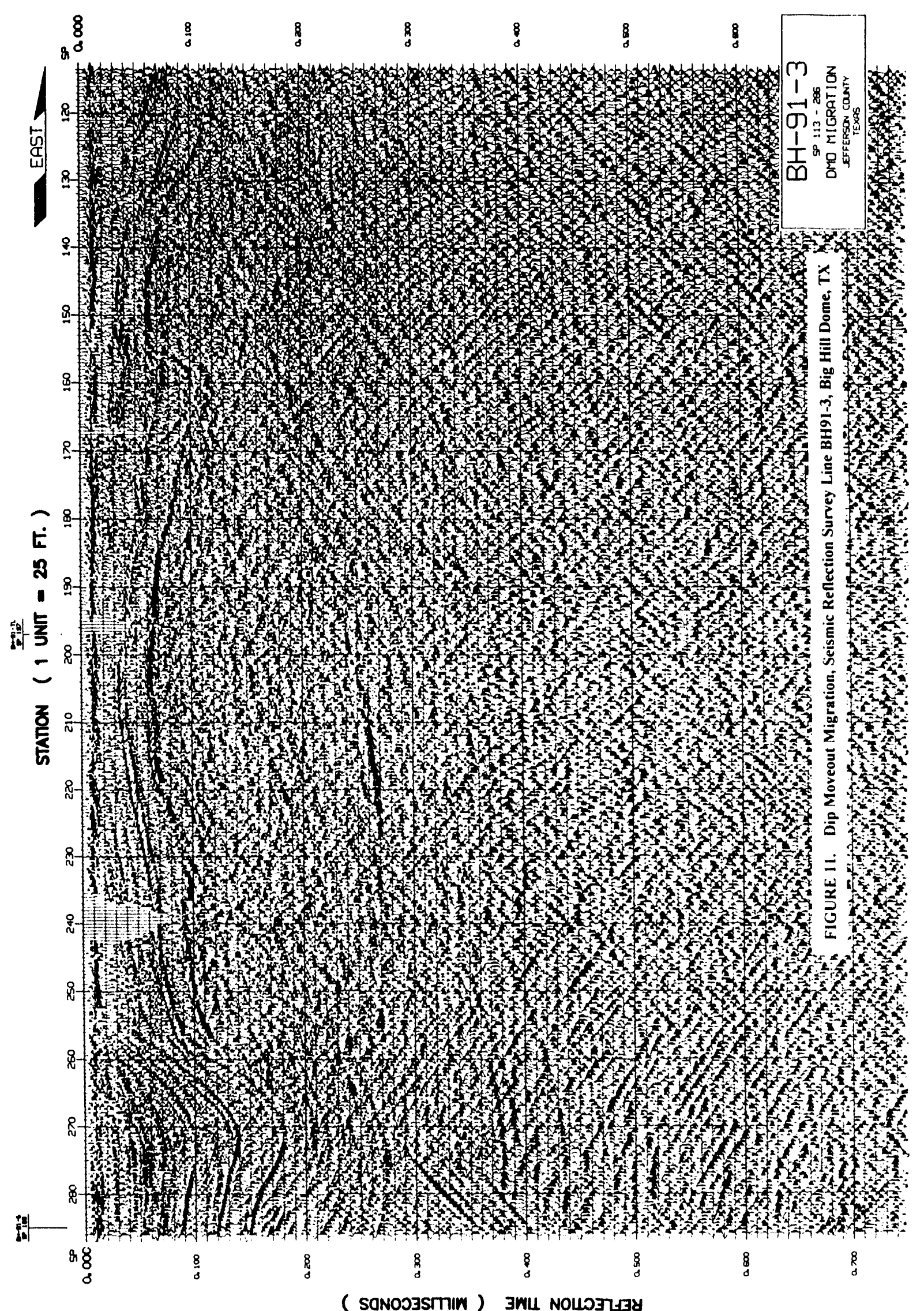

( SONOJISTRIM ) 3WL NOLDJルaY 


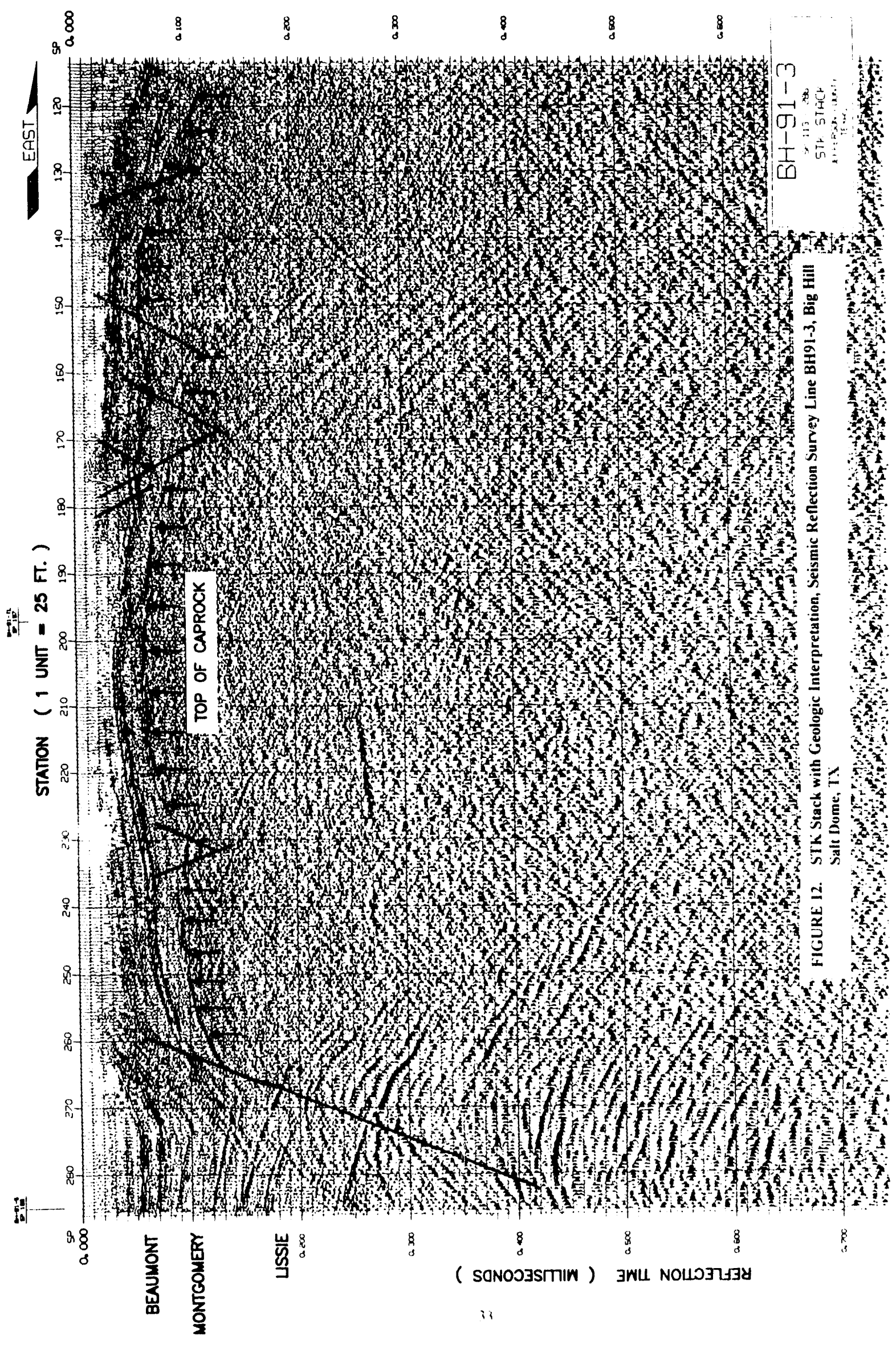




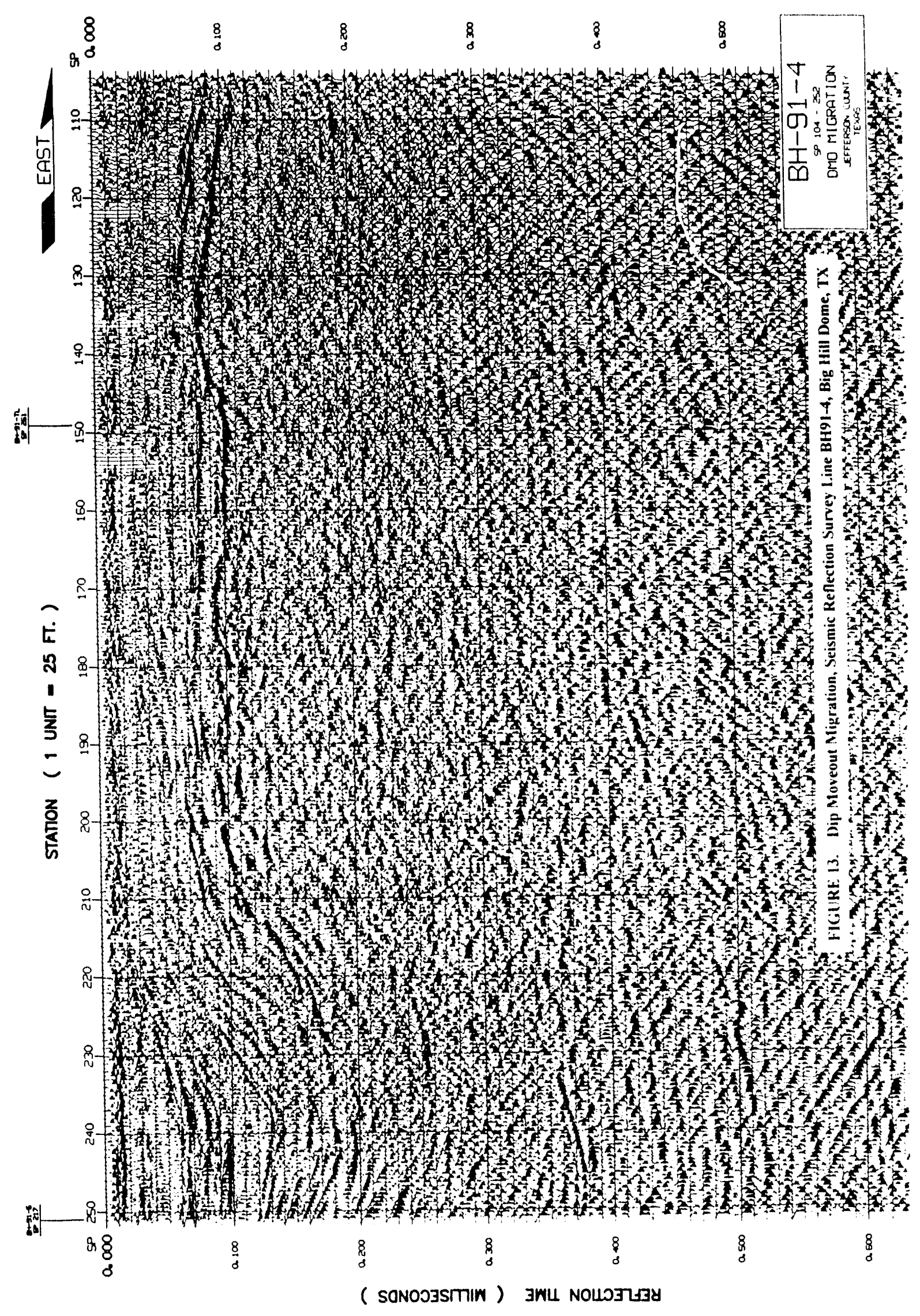




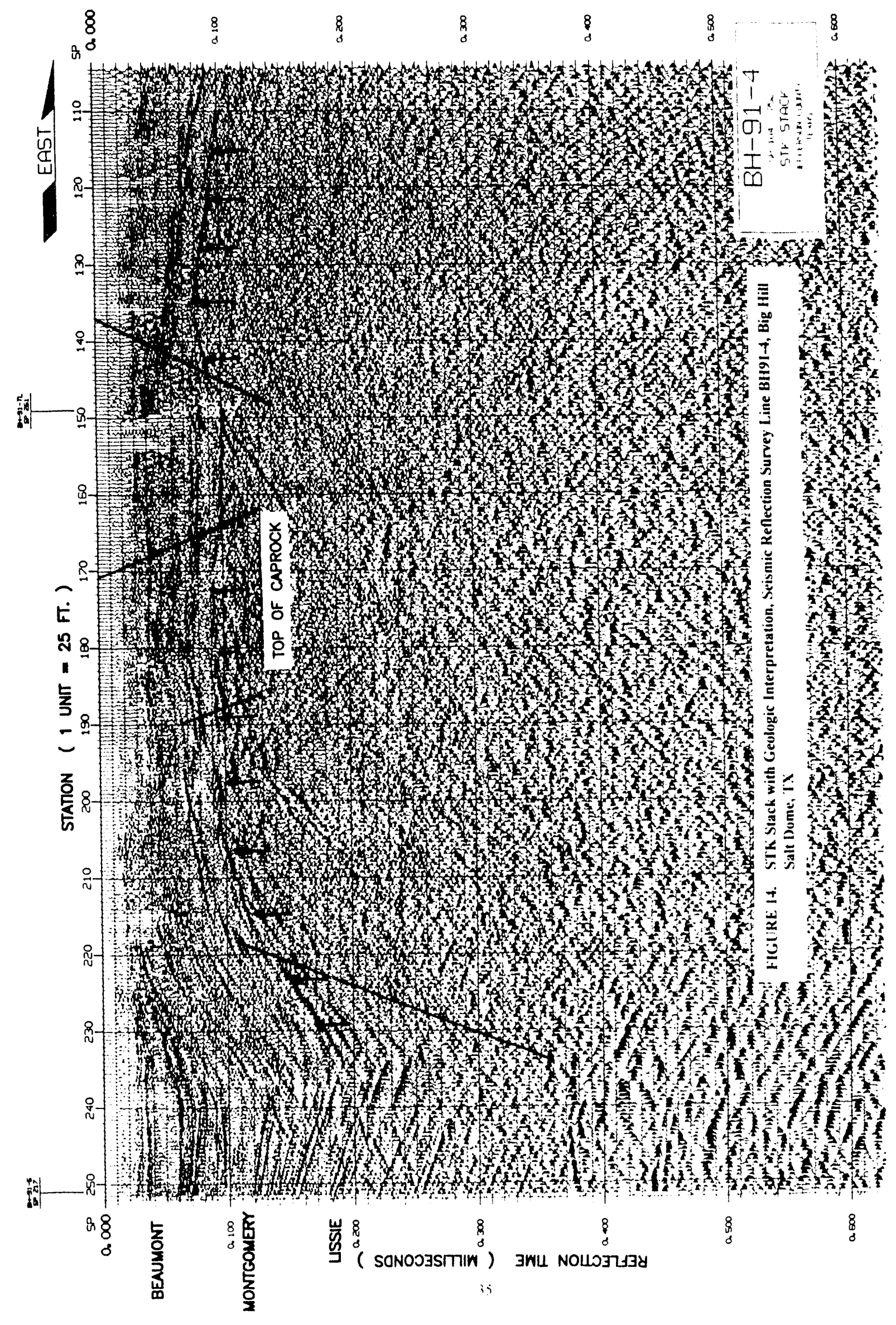




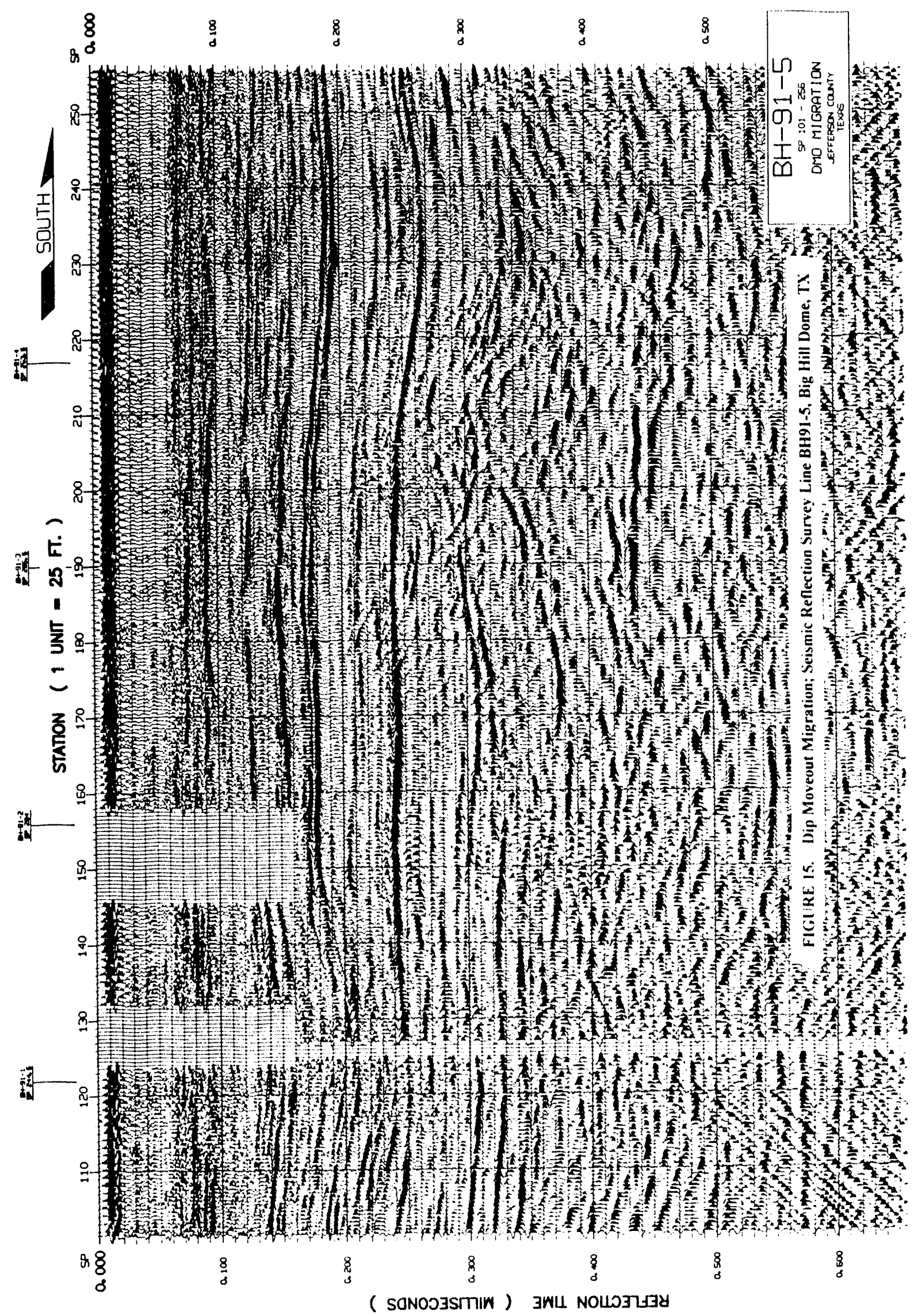




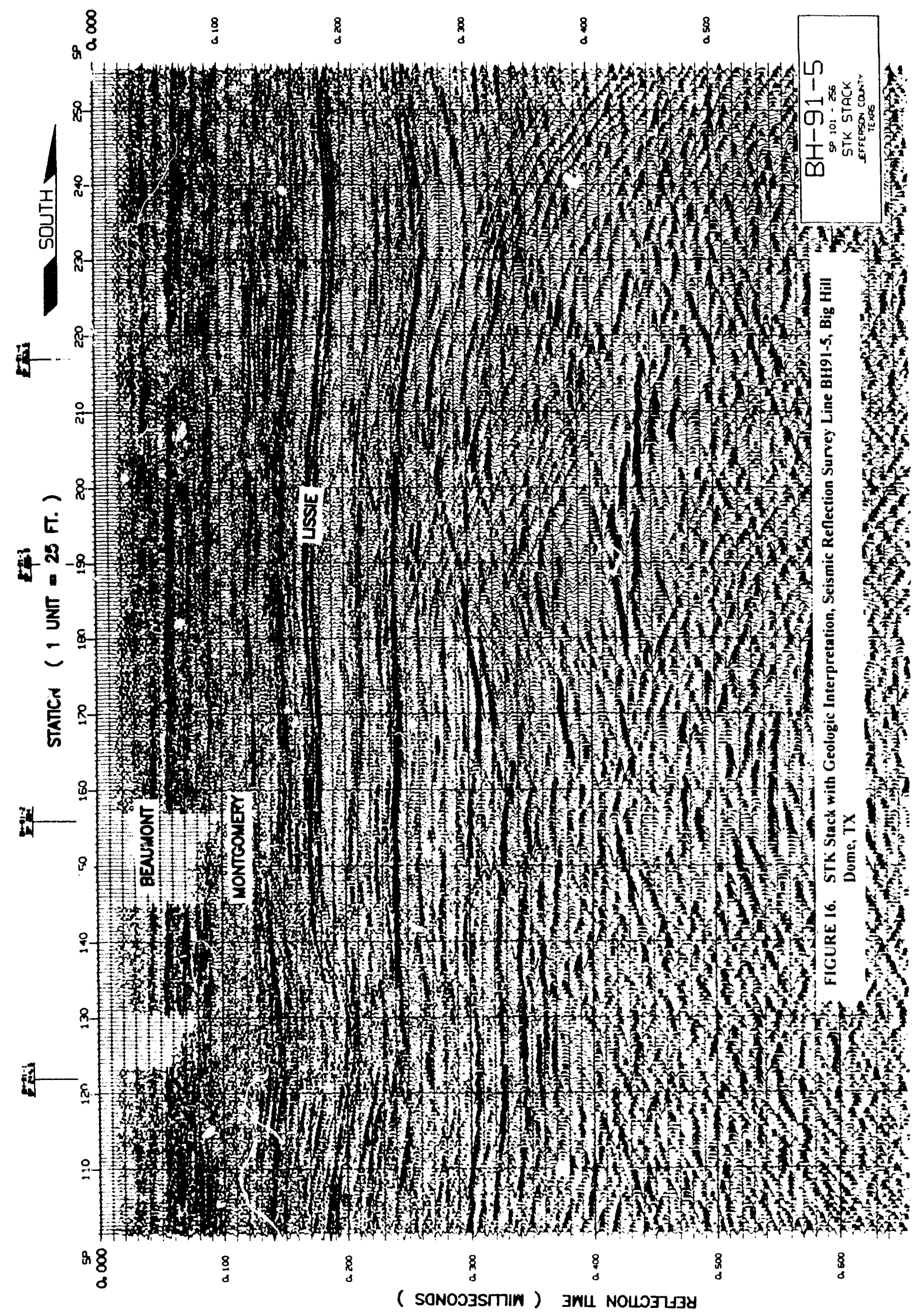




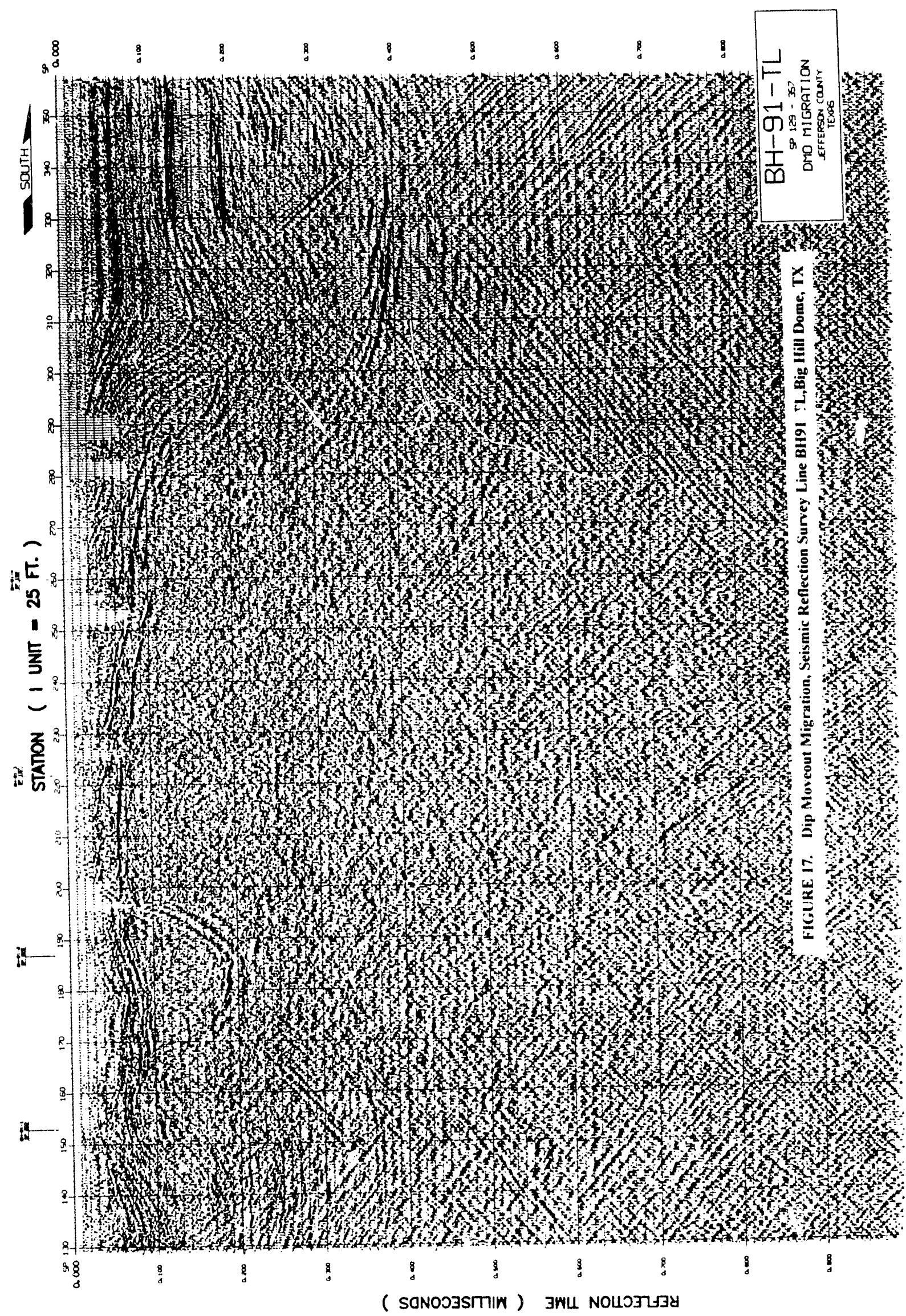




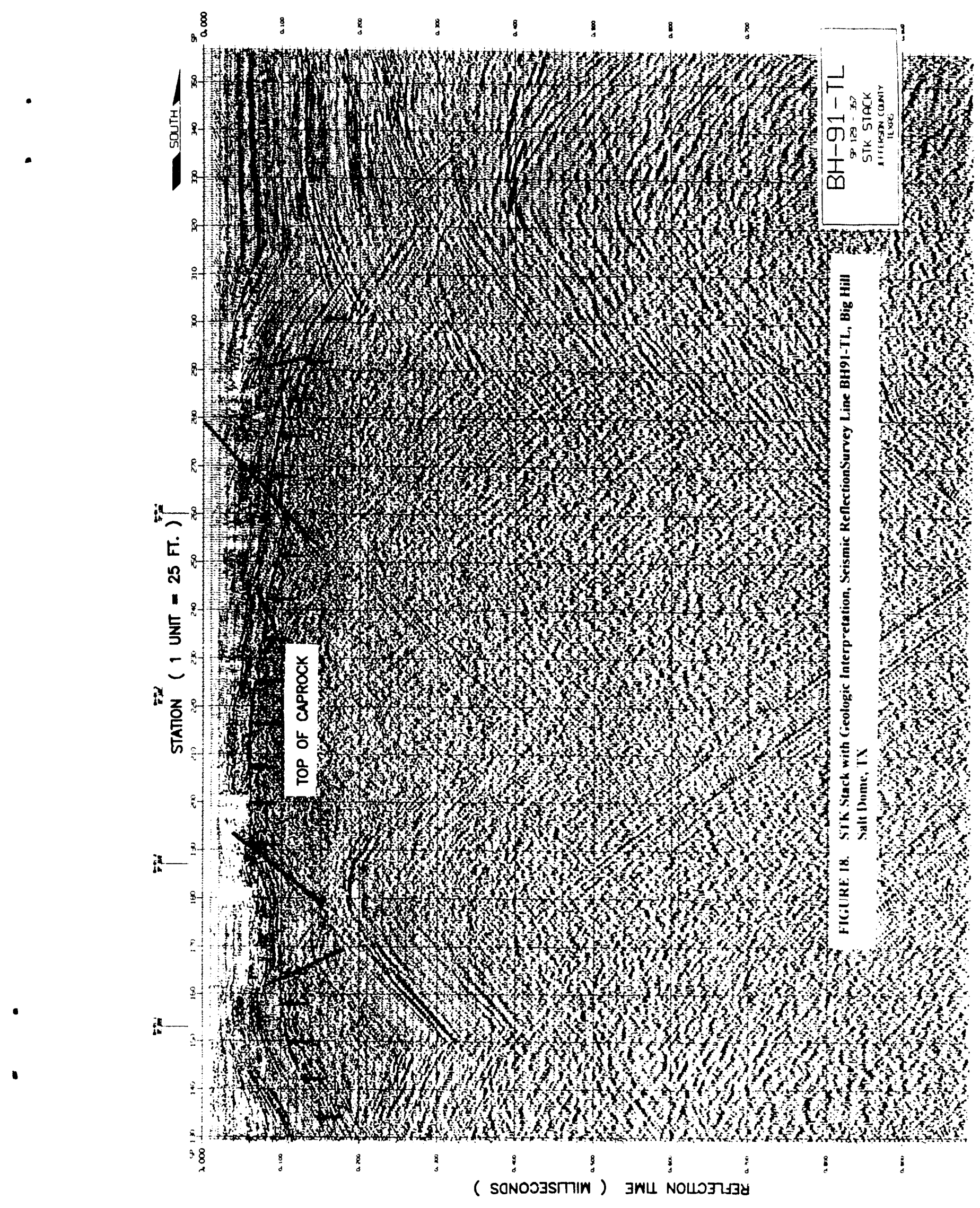


A minor graben lies to the south of the east-west fault on Line 3 (Figs. 5, 12) and other minor faults are found on every line. In interpreting the minor faulting, emphasis has been placed on reflection displacements which can be related on two or more lines. However, even small displacements of the caprock reflector have been mapped where they are definitive. Among these are the down-to-the-northwest fault apparently running over Caverns 109 and the potential location northeast of Cavern 102, two faults parallel to it at the north end of the tie-line terminating in one of the faults found only on line 1; east, northwest and west side bounding faults at the edge of the caprock; a down-to-the-west fault east of Cavern 102; and three minor faults within the graben. These faults are probably typical of what would be found on many domes if subjected to detailed investigation.

A deeper, rather diffuse, reflection below the dead zone of carbonate caprock probably comes fom the massive anhydrite. It has not yet been mapped. Correction for the dramatic velocity changes above may reveal its structure and possibly direct evidence of detailed structure on the top of the salt, which is essentially flat across the top of the dome, as determined from the cavern well control.

The normal rim syncline or thickening in sedimentary beds toward the dome is visible at the ends of the lines and can be related to surface sedimentation, namely the colluvial apron formed of sediment eroded off the hill and deposited just outside the salt stock.

\section{Implications:}

Many more faults were mapped than had been identified previously, which often happens as exploration becomes progressively more detailed. Most of the smaller faults have minor displacement, and can probably be avoided in the placenent of caverns. The many minor faults tend to lack coherency; that is, they are disconnected from each other and from major structural trends. These minor faults probably typify the caprock conditions that may exist at many domes, but have been mapped only infrequently.

We believe that cavern wells should not penetrate known faults in caprock, especially where evidence of activity exists. The intersections of faults, in particular, should be avoided. This condition is present on the Sabine Pass Terminal property, in the expansion row centered $650 \mathrm{ft}$ north of existing Caverns $103 \& 104$. Similarly, the location northeast of Cavern 105 is along the secondary graben described earlier. Further definition of the structure there is warranted, through a combination of geophysics and exploratory drilling. 
The vertical extension of known caprock faults into underlying salt may not be a problem (it may even be undetectable), but even this condition should be questioned prior to emplacement of caverns. This type of condition conceivably could lead to the increased occurrence of gas, such as described in the subsequent chapter and discussion of the anomalous zone at Bryan Mound.

As a result of the survey, the southwest corner of the dome is now better defined than previously, especially in the vicinity of Amoco 8, which was identified as a possible location for a Department of Defense cavern. However, the limited line extension precluded gaining better definition on the northwest overhang.

The central graben and its associated anomalous zone parallel the master fault transecting the dome, a major regional structure which forms the edge of the Hackberry embayment, from High Island to Spindletop to the northeast. The Hackberry embayment formed a sharp edge of continental shelf during the Oligocene with submarine canyons and turbidite sand deposition in fans on the deep ocean floor. This fault, like the Baton Rouge fault at Bayou Choctaw, probably comes from the basement and may be traced to the edge of the continental granitic crust to the west. Hackberry dome and its SPR storage lies in the center of the embayment where the deepwater Oligocene shales at full geopressure have floated up with the salt, forming a sheath and further protecting oil storage near the edge of the salt as high as $3000 \mathrm{ft}$ depth. [Magorian et al., 1991].

\section{EFFECTS OF ANOMALOUS FEATURES (AFS) ON SOLUTION MINING OF STORAGE CAVERNS IN DOMAL SALT}

This Section by R. L. Thoms, AGM Inc.

\section{Introduction}

In view of the fairly large number of solution-mined storage caverns in domal salt, the possibility that some caverns may have intersected anomalous zones, or encountered anomalous features, seems likely. Because the conceptualization of such features has evolved during some 50 years of solution mining, and was confined somewhat to underground conventional mining (and also confined to largely academic geologic literature), the specific 
occurrence of AFs in solution mining has remained somewhat speculative. This section discusses this issue, specifically the occurrence and influence of anomalous features on solution mining of caverns in salt.

Kupfer's 1989 terminology (Table 1, p. 5) is used to describe AFs, based largely on field observations in salt mines. His ten major groups of AFs that are observable in mines are often not monitorable during solution mining of caverns, e. $\mathrm{g}$. large salt crystals and connate brines. Thus, some of Kupfer's AFs are grouped together; for example, anhydrite, shale and/or sandstone are referred to as "insolubles." At least two AFs observed in rock salt mines are also evident in solution mining; i.e., gas releases (mostly $\mathrm{CH}_{4}$ in Coastal Basin domes) and potash (mostly sylvite and carnallite) occurrences. Attention is focused here on three AFs typically noted in solution mining: (1) insolubles, (2) gas, and (3) potash.

Martinez [1992] cautions that some of these features, e. g., potash, may be not uncommon in Gulf Coast domes and that labeling them as anomalies can lead to semantic misunderstanding. Anomalous feature as used here indicates significant and often unexpected departures from generally pure salt.

Operators and constructors of caverns, including geologists, engineers, drillers, and others that were directly involved, were contacted to assemble information regarding anomalous cavern behavior that might be linked to anomalous zones. To aid in free flow of responses within a highly competitive industry, we agreed to not divulge specific sites or companies involved. Thus, some of the information is "generic" in this sense, but not with respect to the technical principles that are involved. In each case that was considered, the following questions (underlined) were addressed:

\section{Concerns and Findings}

\section{(1) What were the specific effects involved?}

a. Short-term (during or soon after leaching) effects were as follows: The presence of insolubles resulted in an increase in the numbers of salt falls during cavern solutioning. Falls by "stringers" or blocks of relatively insoluble materials damaged "hanging strings" used in solutioning. 
Gas releases were handled with "blowout preventers" during drilling or development of wells for caverns. "Gas lift" effects (similar to air-lift effects in sulphur mining and some old brine wells) were sometimes noted during solutioning of caverns. Most of the gas appeared to be methane, but, traces of hydrogen sulfide were also noted. Gas outbursts during solutioning left behind voids in the salt stock, referred to as "wings" or "chimneys" because of their shapes. These may also occur in association with potash. Mills [1992] cautions that some early wings were later proved to be only spurious sonar reflections.

Encounters with potash tended to cause irregular-shape caverns, especially in older operations. In at least one case, caverns were abandoned during solutioning because they were so irregular. Some "wings" or "chimneys" in caverns were probably due to the presence of potash. Potash salts (sylvite, and especially carnallite) are relatively more soluble in halite brines, and will dissolve preferentially along potash-rich layers. According to one scenario, carnallite might dissolve preferentially to form "unseen" (by sonar) channels that could allow "product" to escape from caverns located near the surfaces of salt stocks.

b. Longer-term (life of cavern) effects were as follows: "Salt falls" have been occurring over periods of years in some caverns with large amounts of insolubles. The use of multiple wells to solution mine caverns in anhydrite-rich salt may have caused more falls than in single-well caverns, since more projecting salt ledges vulnerable to falls would occur in vertical trends along multiple well intersections. According to one operator, insolubles are frequently found with gas, and these two AFs may work in concert in a "bowling ball" scenario wherein falls are especially damaging to hanging strings. In this scenario, large blocks of insolubles break away within "wings" formed by gas outbursts. Loose blocks then tumble, "like bowling balls in a lane," and enter the main cavern and impact the hanging strings. Another operator believes pressure waves alone from falling blocks can swing tubing strings against cavern walls and damage them.

Gas releases have also been ongoing for a number of years from some caverns. The flow rates have become significantly smaller with time, but tend to persist where original development wells were recognized as being exceptionally "gassy" (from within the salt stock). Flow rates vary inversely with cavern pressure, i,e., the rates decrease as cavern pressure is increased. Gassy caverns may be inappropriate for storage of some kinds of refined hydrocarbon "products" that can be contaminated by methane. Long-term gas releases may also tend to cause localized disaggregation of salt, and occasional falls, from cavern walls. 
The enhanced solubility effects of potash have been previously noted as impacting cavern shape during solutioning. And, over long time periods, caverns recycled with halitesaturated brines will continue to dissolve potash-rich layers in cavern walls. Thus release channels might be eventually formed by this process for caverns located in potash-rich zones close to salt stock boundaries. This is of special concern if carnallite is the potash mineral present.

(2) What was involved in terms of cost and safety, including lost time by the operator?

Salt falls associated with insolubles sometimes break hanging strings of tubing, which must then be replaced in "workovers." According to one operator, the cost associated with a workover to replace damaged tubing is about $\$ 135,000$. Multiple (e.g., seven) falls that damaged tubing were reported in one cavern. Independent of the cost, and depending on the extent of damage, caverns may be taken off-line (unable to deliver stored product) until the damaged tubing strings are repaired.

The possible presence of gas requires that certain precautions be taken in drilling development and exploratory wells in Gulf Coast salt domes. These precautions are considered standard in Gulf Coast drilling operations for hydrocarbons. For example, at least one operator uses regular "blow-out preventers" and safety procedures (for encounters with flammable gas) that are employed in drilling for oil and natural gas. Care must also be exercised during workovers of gassy wells, since fluids and equipment in the hole may tend to be "gas-lifted." The costs for equipment and procedures to accommodate gas releases depend upon current demand in the oil drilling industry.

The costs associated with potash problems can range up to those for cavern abandonment, or possible loss of product. Cavern construction was abandoned in one area over a dome where the presence of excessive potash resulted in highly irregular cavern shapes. Releases of flammable product along channels solutioned in potash could result in surface damages, including injury to personnel. Thus, the presence of potash (particularly carnallite), for caverns located near dome boundaries, potentially comprises the largest costs associated with the three AFs considered here

(3) Based on current understanding and technology, what could be done in advance (1992) to prevent such occurrences? This question alludes to required geologic site characterization prior to leaching. 
"Occurrences" are interpreted as costly encounters with AFs in storage caverns. These probably can be reduced in number, but not prevented entirely. AFs can occur singly, but frequently tend to be grouped in linear trends in Gulf Coast domal salt. According to Kupfer (1990), the presence of three or more AFs characterize an "anomalous zone," or AZ within a salt stock. AZs can occur on a megascopic scale, and their identification is thus more likely than that of single AFs. Jackson and Talbot (1988), define megascopic features as being more than $1 \mathrm{~km}$ in length.

If caprock is not present over a dome, then "troughs" (linear depressions) and/or aligned "pits" may occur in the top-of-salt surface above major AZs (Acres, 1987). For domes with caprock, such as Big Hill, TX, linear trends of "caprock-offset" may mark the presence of AZs in the underlying salt stock (Magorian and Neal, 1988). Establishing detailed maps of the top-of-salt and/or caprock thus appears useful for identifying AZs. For some domes such maps are already available, but "shallow" data (from regular hydrocarbon exploration) over domes are usually insufficiently detailed to distinguish subtle features that are associated with $\mathrm{AZs}$.

Seismic techniques have been used previously to distinguish relative relief features in the top-of-salt over the Avery Island dome (Black and Voigt, 1982). One experienced operator stated that he would use "high-resolution" seismic technology, coupled with exploratory coreholes, for studying a salt dome before siting a new cavern field in it. Cores and well logs could be examined for AF characteristics, and the findings then checked against the seismic results to identify possible AZs in the salt stock.

Radar has been investigated for locating AFs from within rock salt mines (Unterberger, 1989), and it also has been implemented in boreholes to study salt dome structure (Mundry et al., 1985). Borehole seismic methods and tomography have been used to locate collapse features underground in salt mines, and have been suggested as a method for studying AFs in salt domes (Nelson, 1986).

(4) Realizing that anomalous conditions may be present, or have already been identified, should steps be taken to avoid placing caverns in them?

The decision whether to avoid an $\mathrm{AZ}$ should be based on the site-specific character of the associated AFs and the amount of salt area available for locating caverns. If large areas 
of salt are available, then it appears reasonable to avoid major AZs (if known). In general, according to most operators interviewed, AFs do not justify special measures in relocating caverns. However, the consistent presence of potash (especially carnallite) in a known AZ close to a salt stock boundary appears to justify not placing a cavern there. Excessive anhydrite may also cause long-term problems with salt falls. In addition to possibly relocating a cavern, certain steps can be considered to reduce the frequency of falls in salt with large amounts of insolubles, e. g., well design and completion techniques, limiting rates and magnitudes of operating pressures, etc.

(5) What actions or tests could be undertaken if previously unsuspected behavior that might be related to anomalous zones is experienced? This might include shape irregularities, foreign material, gas pressure buildups, salt outbursts, etc.

As previously noted, potash in the form of carnallite appears to be the AF of most concern in Gulf Coast salt domes. Potash can be detected in salt cores and sometimes identified in well logs. During cavern solutioning the brine returns can be checked for the presence of magnesium and potassium. According to one source, if potash elements are detected in the brine returns during solutioning of caverns, it is prudent to then use abundant amounts of "blanket" fluids. The blanket fluids isolate the cavern roof from the solutioning brine, and prevent the formation of wings and/or chimneys from dissolution of potash-rich salt stringers that may extend upward into the salt stock from the cavern. Another operator used sonar surveys more frequently to check cavern configurations if potash was consistently present during solutioning.

If a cavern appeared to be developing a highly irregular shape, one operator would move up the well to a shallower depth and restart another cavern (provided there was adequate salt above the original location). In some cases, operators abandoned solutioning of caverns that had developed highly irregular shapes. They subsequently moved to another location on the same dome, and developed caverns with shapes that were suitable for storage.

Gas-handling provisions (blow-out preventers, etc.) similar to those used for oil and gas drilling were recommended by cavern constructors for drilling development wells in salt domes. If gas is encountered in the salt stock, the associated flow rates decrease with time and increasing cavern pressure. Gas releases have continued for periods of years from some caverns, while neighboring caverns remained essentially free of gas. Pressure build-ups in storage caverns can be monitored to ensure that operating pressures are not exceeded. 
Stored product can be released, if necessary, to maintain pressures within desired operating limits.

Percentages of insolubles in salt tend to be site-specific to individual wells, but reasonable estimates can be made on the basis of experiences with other wells drilled on the same dome. If larger amounts of insolubles occur than expected, a larger volume of salt must be removed to achieve the "target" storage volume. An unusually large number of salt falls may justify putting certain caverns into semi-active modes. That is, caverns with histories of frequent falls could be cycled less frequently than more stable caverns.

Salt falls tend to occur more frequently in "dry" (non compensated) natural gas storage caverns during periods of low cavern pressures following rapid depressurization. The frequency of falls can be reduced in these cases by limiting flow rates and values of minimum pressure during "draw-down" cycles.

\section{Discussion of the Efrects of Anomalous Zones}

Orientation of layering in domal salt apparently can exert a strong influence on preferential solutioning of caverns. Based on examination of a significant number of sonar profiles, the related effects are most evident in older, more shallow caverns located near boundaries of salt stocks. In a number of older brining operations the tubing strings apparently were left at one depth for some time, and shapes were not closely controlled. Preferred directional dissolutioning of salt then appeared to dominate the resulting shapes of caverns.

Balk (1953) and Muehlberger (1960) noted that the near vertical inclined layering within Gulf Coast mines near salt boundaries tended to be parallel with the edge of the salt stock. Kupfer (1990) also noted layering tended to parallel boundary AZs. Orientation of layering in salt mines can be interpreted using dark marker relic beds or "bands" of salt that are relatively rich in anhydrite. These bands can be readily observed on the surfaces of newly excavated openings, but soon become obscured because of soot deposits from diesel engines used in salt mines. Older (pre-1970s), shallow caverns located near salt boundaries displayed shapes that were frequently elongated in a direction parallel to the stock boundary. Salt formation dissolution generally would appear to proceed more readily in the direction of layering along relatively pure and soluble halite and/or potash layers rather than advancing in 
a direction normal to layering through intervening screens of less soluble, anhydrite-rich salt. The presence of caverns with elongated cross-sections thus implies that layering occurs locally in a direction parallel to the elongate axis of the caverns. Therefore cavern shapes that are elongated parallel to dome boundaries tend to corroborate reports from mines that, in the vicinity of salt stock boundaries, layering tends to be parallel to the boundaries.

Several constructors of caverns noted that potash was more likely to be encountered near outer boundaries than in the central part of salt stocks. This was evident in the McIntosh salt dome, located north of Mobile, AL (Medley, 1989). An exploratory well encountered sylvite and carnallite near the western edge of the dome, whereas a development well drilled for a compressed air energy storage (CAES) cavern in a more central location over the dome encountered typical Gulf Coast domal salt, i. e., halite with modest $(<8 \%)$ anhydrite. Apparently some very large salt crystals ( $>12$ in) were also visible in cores taken from the exploratory well. Kupfer (1990) has designated large salt crystals to be an anomalous feature and has observed that they can occur in the proximity of salt stock boundaries, i.e., in "edge AZs".

\section{Example of Anomalous Features at a Gulf Coast Salt Dome}

The Bryan Mound salt dome near Freeport, TX, was selected as an example dome to illustrate some of the previously discussed effects associated with AFs. The Bryan Mound dome is used for crude oil storage in the U. S. Strategic Petroleum Reserve (SPR) program. Significant amounts of data are thus available from previous studies performed for the SPR, e.g., D'Appolonia [1980].

Figure 19 shows the Bryan Mound salt stock and the caverns within it. The initial (Phase I) Caverns 1, 2, 4, and 5 are more irregular and larger in plan view than the later Phase II and III caverns (Cavern 3 was judged unsuitable for the SPR program). At the time the 1980 report was produced the Phase II development wells 101-112 had been drilled, but the caverns had not been constructed. The caverns were thus depicted schematically as circles, and the wells for Caverns \#113-116 had not been drilled and were depicted as dashed circles.

The dashed red lines in Fig. 19 represent trends of AFs in the Bryan Mound salt stock that were presented by D'Appolonia [1980]. These findings were based on existing conditions within the Phase I caverns, and on examination of cores taken from the Phase II 


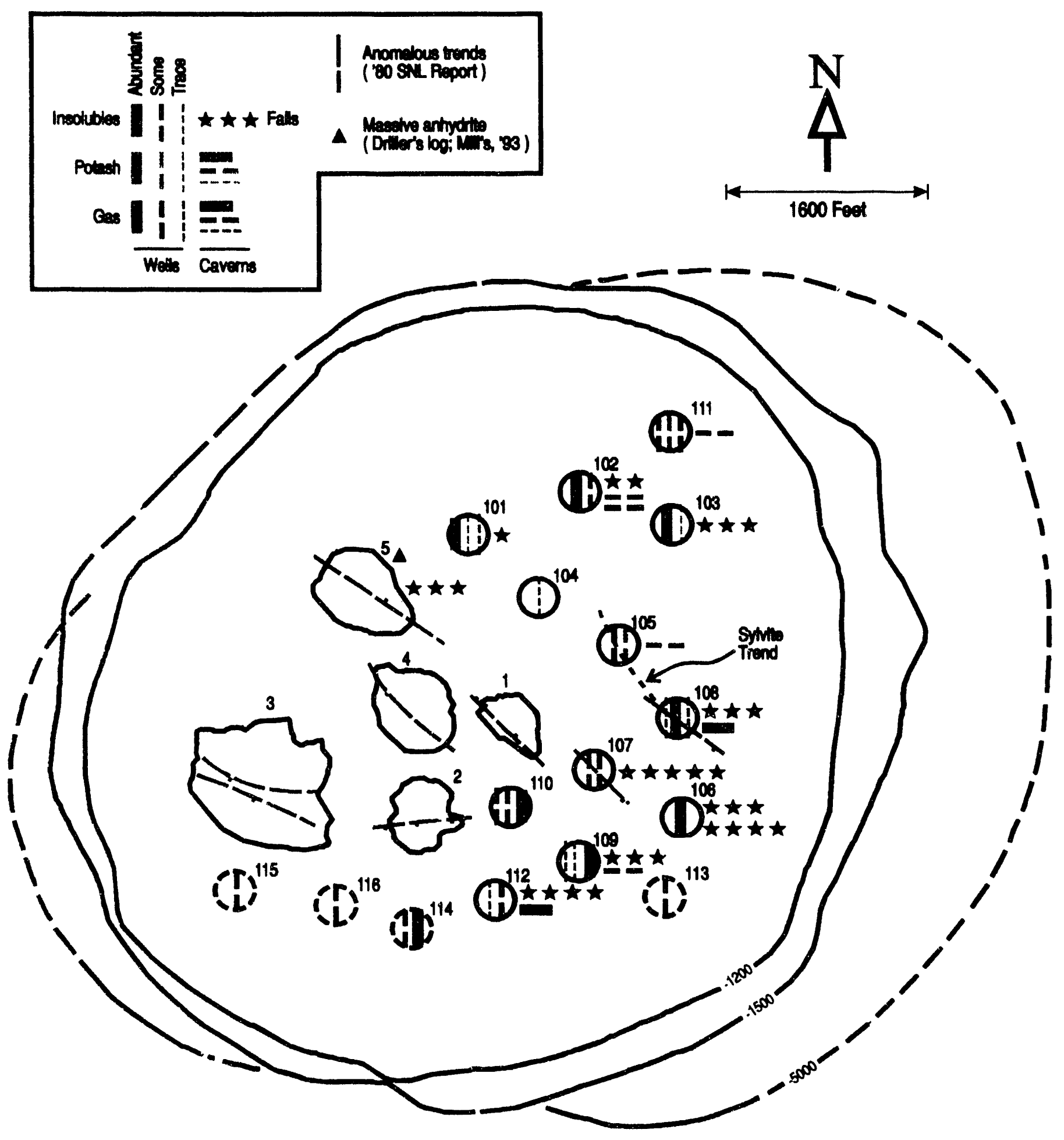

FIGURE 19. Anomalous Features, Bryan Mound Dome 
wells. The lines denote both dip and strike of AFs that included occurrences of anhydrite and shale (insolubles), potash, and gas. More specifically, a trend of potash, i.e., "sylvite anomalies", was speculated to occur between Caverns 108 and 105, as indicated by the dashed grey line in Fig. 19.

Figure 19 further depicts the occurrences of AFs noted in wells and cores drilled for the development of Phase I and II Caverns [D'Appolonia, 1980 and IT, 1984]. Included are related gas effects observed later in caverns at the same sites [Boeing, 1991]. Potash during cavern solutioning was based on percentages reported in brine returns [SPR library, New Orleans]. Numbers of falls were reported from the Bryan Mound site [Bakhtiari, 1992, and K. Mills, 1993]. Symbols within cavern schematics represent AFs based on the well drilling program; those on the right-outside represent effects during and following cavern solutioning. Occurrences of insolubles (mainly anhydrite), potash, and gas during drilling are denoted respectively by magenta, gold, and green colored vertical line segments within cavern circles. Numbers of falls, percentages of potash in returns, and abundance of gas during and following solutioning, are denoted by the stars, gold, and green symbols on the right side of the cavern circles. Note that only the number of falls have been quantified. Otherwise, relative amounts (i.e., trace, some, abundant) of AFs based on observational data are noted schematically in Fig. 19.

In general, the AFs noted in the wells resulted in related effects in the caverns. Cores from Cavern 108 exhibited large amounts of potash (sylvite), as did the brine returns from the cavern during solutioning. However, the abundant sylvite apparently did not result in an unusually irregular shape for Cavern 108 [Boeing, 1991]. Abundant amounts of gas were noted during pilot drilling for Cavern 109, but only "some" was noted in the pilot drilling for Cavern 112. But when the caverns were developed, 112 was clearly the "gassiest" of the lot, and apparently continues to release significant amounts of gas.

Significant numbers of salt falls are probably due to a number of factors including: amount and distribution of insolubles in the salt, gas, and solutioning-of-cavern technique. The "worst case" for long-term falls would be the following combination: significant amounts of concentrated insolubles occurring near the top of a cavern, continuing gas releases, and "parallel" cavern development from three wells. Concentrations of insolubles (e. g., solid anhydrite in the forms of stringers and/or boudinages) would tend to break off as blocks during solutioning, as contrasted to distributed insolubles that would fall down in the cavern as individual crystals. Blocks of materials falling from high in the cavern would have a larger 
distance over which to impart momentum to hanging strings via pressure waves transmitted through tint brine and/or oil. This would then increase the likelihood of the strings swinging to the extent that cavern walls were impacted. Gas releases would tend to disaggregate salt and cause blocks to break away (especially if concentrated insolubles were present). Also, as not $\mathrm{d}$ pieviously, the siniultaneous use of muliple wells for cavern development would result in vertical trends of salt projections along the well intersections. Furthermore, the use of three wells in solucioning would tend to leave a central salt "stringer" that would collapse into the cavern at sorne point. thus, based soleiy on their configurations, the three-well caverns at Bryan Mound r.ppear generally to have a greater potential for falls than the two-well caverns.

witi، reference to Figure 19, three-well development effects probably contributed to the number of falls that have occurred in the proup of four caverns, \#106-109, on the southeast portion of the dome. Cavern 106 has exhibited the most falls (seven) of all caverns, Cavern 107 is ir second place with five, and Caverns 108 and 109 have had three (each). Effects of the three-well cievelopment of \#106 can be seen in sonar logs in the form of three inward projecting corners of salt at the well intersections. These corners extend vertically over a significant portion of the cavern. In the 1980 Report, the logs for well \#106C indicated that anhydrite-rich salt occurred in a concentrated form near the top of the cavern (between 2000 and 2300 feet) This kind of occurrence is most suspect for later falls that damage hanging strings in caverns. In \#107, no insolubles were indicated, but enough gas and potash were detected to project an anomalous trend in the 1980 report. And as discussed later, Caverns 106 and 107 are speculated to lie in a major anomalous zone trending across Bryan Mound dome. Thus AFs not present in cores may have been encountered in the larger radii of the caverns. The remaining three-well Caverns 104 and 110 have had no falls, which contravenes the suspected association of three-well cavern development and falls. In Cavern 104, core anaiyses indicated only trace amounts of insolubles, and no gas or potash, and these "good" conditions likely ameliorated the tendency for falls. The lack of falls in \#110 is most surprising, sinci the core analyses implied all the conditions usually associated with falls were present in the surrounding salt.

Among the two-well (development) caverss, \#112 has he ted the most falls (four, and possibly five). Although the well cores displayed only traces of insolubles, the developed cavern exhibits significant ongoing gas intrusion, which is a feature frequently linked with falls. The cores for the two-ivell Caverns 101-103 displayed "abundant" amounts of insolubles, and the caverns have experienced one, two, and three falls, respectively. No falls have occurred in the two-well caverns \#105 and \#111, with cores that displayed "some" 


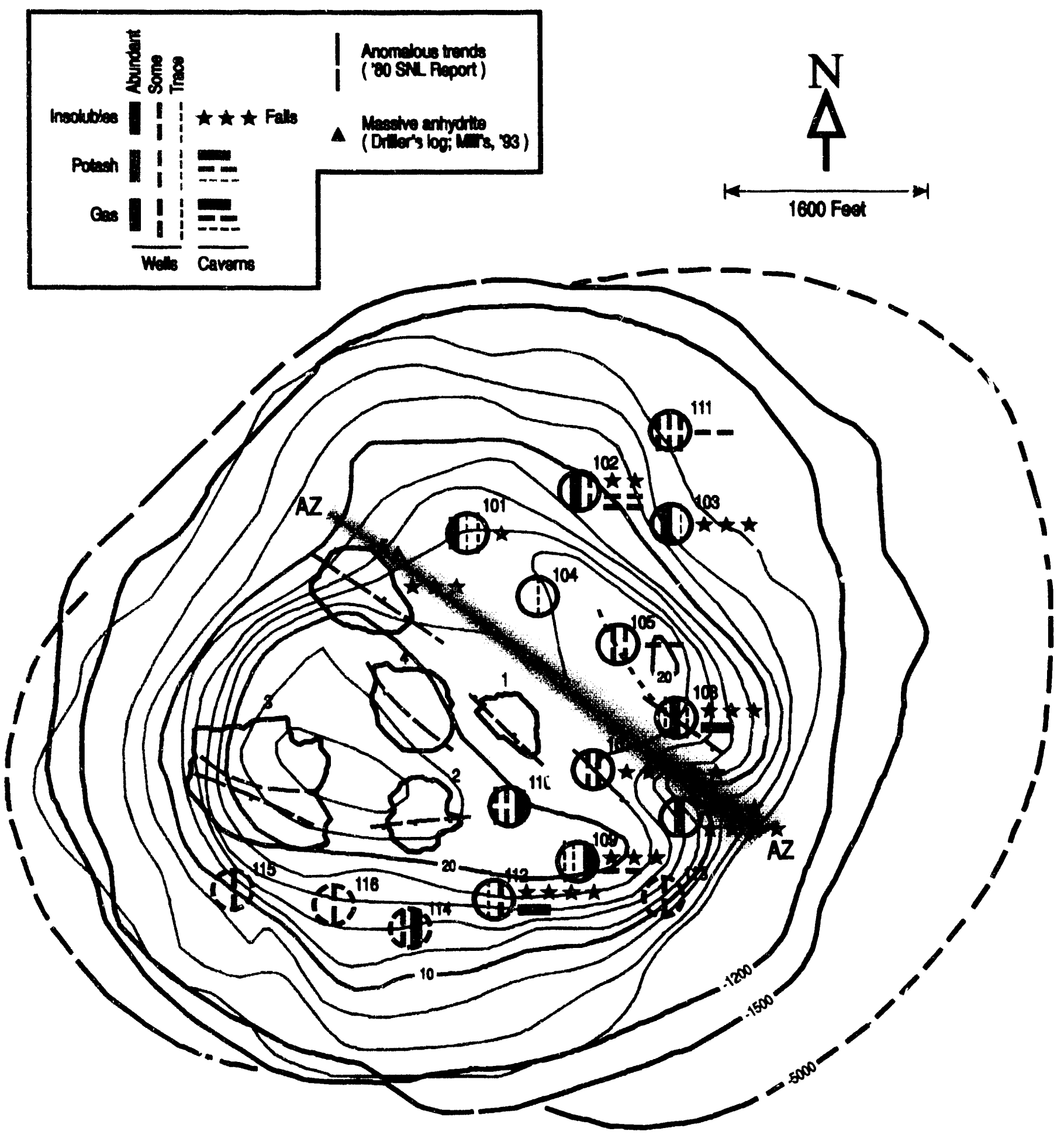

FIGURE 20. Suggested AZ, 1925 Surface Contours, and Anomalous Features; Bryan Mound Dome 
anhydrite. Based on core descriptions, the salt surrounding Caverns 105 and 108 should be similar. They also both lie on a speculated trend of sylvite. However, \#108 is a three-well cavern, and its resultant configuration thus likely contributed to its having three falls, which contrasts with none for $\# 105$.

The possibility of a major AZ across the Bryan Mound salt stock was discussed in some detail in the D'Appolonia [1980] report, although "shear zone" was used rather than "AZ." The trends indicated in Fig. 19 by the red lines represented the summary findings in livis regard. In preparing this report, a number of characteristics of the dome were reviewed in searching for possible "indicators" of AZs. Thus, the top-of-salt and top-of-caprock maps from the 1980 report were superposed over the dome stock/caverns map of Fig. 19, but nothing was found to suggest a southeast to northwest (SE-NW) AZ trend across the dome. However, superposition of a 1925 ground-surface topography produced the suggestive image depicted in Figure 20. The 1925 topography was surveyed before sulphur mining had much impact on the naturally occurring surface features over the dome. The obvious SE-NW trending surface relief ranged over only about $24 \mathrm{ft}$, which suggests that relatively subtle indicators may need to be identified in searches for AZs. Perhaps more detailed top-of-cap and/or top-of-salt maps would also have indicated the presence of $A Z$ trends. In any case, based on the surface contours of Fig. 20 and the AFs represented in Fig. 19, it appears likely that Caverns 106, 107, and 108 are located in a major AZ trending SE-NW across the salt stock of the Bryan Mound dome. A tentative location for such an AZ is depicted schematically in Fig. 20.

The speculative $\mathrm{AZ}$ illustrated in Figure 20 does not account for all of the anomalous features observed in the Bryan Mound caverns. However, anomalous features in general are not confined to AZs. Also, the presence of more than one $A Z$ in a salt stock is not uncommon. For example, multiple AZs have been postulated for the Weeks Island dome (Figs. 2 and 3). Thus, a minor AZ may wrap around the southern portion of the Bryan Mound stock to incorporate Caverns 112 and 109. Caverns 102 and 103 may also be located in a minor $\mathrm{AZ}$ on the northeast side of the dome. The identification of minor $\mathrm{AZs}$ in domal salt stocks is somewhat subjective even when the supporting data are collected in rock salt mines. It thus appears unlikely that minor AZs can be identified using data collected largely from outside a stock. On the other hand, the possibility of identifying major AZs, and trends of multiple AFs, by drilling/coring and other previously noted techniques appears promising. 


\section{CONCLUSIONS}

The conceptualization of anomalous features and zones in Gulf Coast salt domes has progressed as increasingly more and improved data has become available during the construction of nearly 1000 caverns, numerous exploratory wells, and a dozen or so salt mines. Improved data has been one result of modern technology, and new interpretations that were not possible 20 years ago have been forthcoming. While underground mine workings have provided the best platform for direct observation of anomalous features, geophysics (including sonar profiles), well logs, core samples, and brine returns now are able to confirm their presence in well bores and caverns. Such features should be expected as the rule and not the exception in future cavern development. The following generalizations appear appropriate:

The recognition of anomalous features and zones may require the understanding of geologic subtleties, such as topographic/geomorphic, hydrologic, or pedologic indicators of underlying salt conditions. The presence of such indicators often implies differential movement in the salt mass, and that often the features reveal the boundary between different salt segments.

Whereas surficial manifestation of shear zones had been previously identified in soils at Avery Island, those shears which were recognized in some subsurface core profiles at Weeks and Cote Blanche Islands failed to establish a conclusive relationship with internal salt dome structure. This resulted partly from the limited amount of sampling that could be accomplished, and perhaps from the more sandy soils at Weeks. However, surface topography at Weeks Island, between the Devils Backbone and adjacent Sandy Bottom Pond, corresponds in general with a major structural anomalous zone which has been observed underground. The evidence suggests that this is the boundary between major spines, or lobes, which reflect differential movement of the rising salt mass.

The Big Hill seismic reflection results indicate a major graben structure in the caprock that transects the entire dome from southwest to north-northeast. An east-west trending fault of smaller, yet not insignificant size, was seen intersecting the main graben just north of the current caverns and immediately northeast of Cavern 104. The major graben extends into the salt and was previously identified as an anomalous zone on the basis of correlation of anhydrite banding, but it may not affect cavern development significantly. These major fault structures should be avoided, if at all possible, when it is necessary to install well casings 
through the caprock. Otherwise, special casing must be used, with exceptional wall thickness. Minor faulting in the caprock was found on all the lines and this probably would have little bearing on the locations of caverns.

The anomalous feature of greatest concern to cavern constructors and operators is the presence of potash zones, especially carnallite, near salt stock boundaries. However, the presence of potash in salt domes is not necessarily anomalous, but rather common. The presence of potash had also resulted in concerns with irregularly shaped caverns in a central area within one dome. In this case the potash area occurred in the salt beneath an intersection of offset trends in the overlying caprock. Salt falls can also pose costly longterm effects by requiring continuing repairs of hanging strings in caverns. Gas releases can be adequately managed during drilling and solutioning in Gulf Coast domes with existing technology.

The example of Bryan Mound was used to show that caverns situated in domes with anomalous zones may experience more gas outbursts and associated salt falls than in caverns situated in more homogeneous salt. The association of anomalous zones with gas in salt is poorly understood at this time. The lesson learned at Bryan Mound, while not understood at the time of cavern emplacement, is that salt with known or suspected anomalous features should be characterized more completely during the initial study phase, and during conceptual design prior to cavern development. This event sequence could be expected to occur during the initial period in which operators and managers may be pressed to rapid actions to get facilities on-line, but also one that ultimately may prove critical in determining profit margins, or which could affect safety.

No new information was gained about Weeks Island that would suggest the dome would present problems for leached caverns. The projected extension of the major east-west trending shear zone needs to be studied further prior to cavern siting. However, on the basis of experience at other domes, if adverse salt conditions are encountered in the vicinity of the anomalous zone, it should be possible to shift cavern locations to avoid them.

The correlation of internal shear features and anomalous zones with major regional structural trends is evident at all of the SPR sites, and is likely to occur at other salt domes. This internal/external feature correlation requires additional conceptual development, as previous investigators have considered anomalous zones to be features related principally to deposition and composition, and to diapirism. We believe that salt spine movement occurs in 
conjunction with the same tectonic forces which create underlying salt ridges and sills, and which control regional fault trends.

The knowledge gained which shows that anomalous features and zones are present generally does not justify special measures in relocating caverns, other than perhaps minor shifts. When large areas of salt are available, it is preferable to avoid stock or dome boundaries, and to not locate caverns in known, major anomalous zones. The actual placement of caverns should be done with deliberation, and only after geologic site characterization has established specific conditions.

Finally, to place the subject of anomalous zones into proper perspective, we believe the consideration of dome edge buffer distances is far more significant in cavern siting decisions. Our experience and intuition tells us that far more problems are encountered at the dome edge than in the salt stock interior. As a result, at locations where anomalous zones intersect the dome edge, particular caution should be exercised.

\section{ACKNOWLEDGEMENTS}

We are indebted to Drs. Joseph D. Martinez and Donald H. Kupfer, Professors Emeritus at Louisiana State University, who have generously given their time to review this report, but we especially appreciate their ideas. Similarly, Ken Mills of DynMcDermott Petroleum Services gave many hours in sharing his experience and ideas, and in reviewing the report. Through this spirit of cooperation and mutual sharing of knowledge, our conceptual understanding of salt domes is moving forward.

\section{REFERENCES}

Acres International Corp. (1987) Weeks Island Strategic Petroleum Reserve Geological Site Characterization Report; Sandia National Labs. Report SAND87-7111.

Atwater, G. I., and M. J. Forman (1959) Nature and Growth of Southern Louisiana Salt Domes and Its Effect on Petroleum Accumulation. Am. Assoc. Pet. Geol. Bull. 43, p. 25922622.

Autin, W. J. (1984) Observations and Significance of Sinkhole Development at Jefferson Island. Geol. Pamphlet No. 7, Louisiana Geol. Surv., Baton Rouge, 75 pp. 
Autin, W. J., R. P. McCulloh, and A. T. Davison (1986) Quaternary Geology of Avery Island, Louisiana. Trans. Gulf Coast Assoc. of Geol. Societies, 36: 379-390.

Autin, W. J. and R. P. McCulloh (1993) Quaternary Geology of Weeks and Cote Blanche Islands Salt Domes. Louisiana Geol. Survey, Baton Rouge; Contract 87-7671 with Sandia Nat'l. Labs.

Balk, R. (1949) Structure of Grand Saline Salt Dome, Van Zandt Co., TX. Amer. Assoc. Pet. Geol. Bull. 33: 1791-1829.

Balk, R. (1953) Jefferson Island Salt Dome, Louisiana: Amer. Assoc. Pet. Geol. Bull., 37: 2455-2477.

Bakhtiari, H. (1992) Personal communication, Bryan Mound SPR site. Updated 9 April 93 memo, on history of Bryan Mound casing failures. DynMcDermott, Cavern Engineering Report.

Black, W. E., and J. D. Voigt (1982) The Use of Seismic Refraction and Mine-to-Surface Shooting to Delineate Salt Dome Configuration and Map Fracture Zones: Soc. Explor. Geophys., 52nd Ann. Mtg., Dallas, p. 465-6.

Boeing Petroleum Services (1991) DOE SPR Constructed Cavern History, Rev. 2: U. S. Department of Energy Strategic Petroleum Reserve, New Orleans.

D'Appolonia Consulting Engineers, Inc. (1980) Geological Characterization, Bryan Mound Salt Dome, Brazoria County, TX: Sandia National Laboratories Rept. SAND807111 .

Dollison, R. S. (1965) Big Hill Field, Jefferson County, TX. Trans. Gulf Coast Assoc. Geol. Soc., 15: 25-35.

Heald, K. C. (1924) Sandstone Inclusions in Salt in Mine on Avery's Island. Amer. Assoc. Pet. Geol. Bull. 55: 674-676.

Howard, J. C. (1971 Computer Simulation Models of Salt Domes. Am. Assoc. Pet. Geol. Bull., 55: 495-513.

Iannacchione, A. T. et al. (1984) Assessment of Methane Hazards in an Anomalous Zone of a Gulf Coast Salt Dome. U. S. Bur. Mines Report of Investigations No. RI-8861.

IT Corp. (1984) Review and Evaluation of Strategic Petroleum Reserve Well Histories and Cavern Sonars, Draft Report to Sandia Nat'l. Labs.

Jackson, M. P. A., and C. J. Talbot (1986) External Shapes, Strain Rates, and Dynamics od Salt Structures: Geol. Soc. Amer. Bull., 97: 305-323. 
Jackson, M. P. A., et al. (1990) Salt Diapirs of the Great Kavir, Central Iran. Geol. Soc. Amer. Mem. 177, 139 pp.

Kupfer, D. H. (1962) Structure of Morton Salt Company Mine, Weeks Island Salt Dome, Louisiana. Am. Assoc. Pet. Geol. Bull., 46: 1460-1467.

Kupfer, D. H. (1963) Structure of Salt in Gulf Coast Domes. 1st Symposium on Salt; N. Ohio Geol Soc., Cleveland, p. 104-123.

Kupfer, D. H. (1974) Boundary Shear Zones in Salt Stocks. 4th Symp. on Salt; N. Ohio Geol. Soc., Cleveland, p. 215-225.

Kupfer, D. H. (1976) Shear Zones inside Gulf Coast Salt Stocks Help to Delineate Spines of Movements. Am. Assoc. Pet. Geol. Bull., 60: 1434-1447.

Kupfer, D. F. (1980) Problems Associated with Anomalous Zones in Louisiana Salt Stocks, USA. In 5th Intl. Sympos. on Salt (Hamburg, Germany, 29 May - 1 June 1978); N. Ohio Geol. Soc., Cleveland, 1: 119-134.

Kupfer, D. H. (1988) The Internal Structure of the Five-Island Salt Domes. In Avery and Jefferson Islands Guidebook; Houston Geol. Soc;; Am. Assoc. Pet. Geol. Convention field trip.

Kupfer, D. H. (1989) Internal Kinematics of Salt Diapirs: Discussion. Am. Assoc. Pet. Geol. Bull., 73: 939-942.

Kupfer, D. H. (1990) Anomalous Features in the Five Islands Salt Stocks. Trans. Gulf Coast Assoc. of Geol. Soc., 40: 425-437.

Kupfer, D. H. (1992) Personal communication, including sharing of Table 1, which reflects currentmost conceptions of AZs.

Magorian, T. R., J. T. Neal, S. Perkins. Q. J. Xiao, and K. O. Byrne (1991) Strategic Petroleum Reserve (SPR) Additional Geologic Site Characterization Studies: West Hackberry Salt Dome, Louisiana. Sandia National Labs. Report SAND90-0224.

Magorian, T. R. and J. T. Neal (1988) Strategic Petroleum Reserve (SPR) Additional Geological Site Characterization Studies: Big Hill Salt Dome, Texas. Sandia National Labs. Report SAND88-2267.

Martinez, J. D. (1992) Personal communication, following review of this report; Baton Rouge, LA.

Medley, A. H. (1989) Status of McIntosh, Alabama, 110 MW CAES Project, presented at Solution Mining Res. Inst. Spring Mtg., Austin, TX. 
Mills, K. E. (1992, 1993) Personal communication and assistance in interpreting percentages of potash from brine-returns reports from Bryan Mound caverns: Boeing Petroleum Services (now DynMcDermott Petroleum Operations Co.), New Orleans, LA. Bryan Mound has shown an anomalously high number of salt falls as compared with other sites. Big Hill Cavern 114 anomalous behavior is reported on in BPS letter 5-0119-KEM-89251.

Molinda, G. M. (1988) Investigations of Methane Occurrence and Outbursts in the Cote Blanche Domal Salt Mine, Louisiana. U. S. Bur. Mines Rept. of Investigations No. RI-9186; Pittsburgh, PA.

Muehlberger, W. R. (1960) Internal Structure and Mode of Uplift of the Grand Saline Salt Dome, Van Zandt Co., TX, USA. 21 st Int'l. Geol. Congr., Copenhagen. 18: 28-23.

Mundry, E. R., R. Thierbach, F. Sender, and H. Weichart (1985) Borehole Radar Probes in Salt Deposits; 6th Int'l. Symp. on Salt, The Salt Institute, Alexandria, VA, 1: 585599.

Nelson, J. S. (1986) Geophysical Measurements in Salt; Past, Current, and Future. Presented at Solution Min. Res. Inst. Spring Mtg., Baton Rouge, LA.

Talbot, C. J. and M. P. A. Jackson (1987) Internal Kinematics of Salt Diapirs. Am. Assoc. Pet. Geol. Bull., 71: 1068-1093.

Thoms, R. L. and J. D. Martinez (1980) Blowouts in Domal Salt. In 5th Intl. Sympos. on Salt (Hamburg, Germany, 29 May - 1 June, 1978); N. Ohio Geol. Soc., Cleveland, 11: 119134.

Unterberger, R. R., and M. Thornton (1989) The Use of Ground Probing Radar in Mines and Quarries, presented at Solution Min. Res. Inst. Spring Meeting, Austin, TX.

U. S. Department of Energy (1991) Report to the Congress on Expansion of the Strategic Petroleum Reserve to One Billion Barrels; Office of Strategic Petroleum Reserve, Washington, DC, Report No. DE/FE-0221P.

Walker, C. (1992) High Resolution Seismic Survey at Big Hill Dome. Presented at Solution Min. Res. Inst. Fall Mtg., Houston, TX. 
Distribution:

U.S. DOE SPR PMO (9) 900 Commerce Road East New Orleans, LA 70123 Attn: J. C. Kilroy, FE-433

J. W. Kunkel, FE-4422

R. E. Myers, FE-4422 (3)

L. J. Rousseau, FE-433

N. W. Smith, FE-4441

TDCS (2)

U.S. Department of Energy (3)

Strategic Petroleum Reserve 1000 Independence Avenue SW Washington, D.C. 20585

Attn: R. Smith

D. Johnson

D. Buck

DynMcDermott (6)

850 South Clearview Parkway

New Orleans, LA 70123

Attn: T. Eyermann

J. McHenry

K. Mills

H. Kubicek

J. Teerling

K. Wynn

Acres International Corporation (3) 140 John James Audubon Parkway Amherst, NY 14228-1180

Attn: B. Lamb

S. Thompson

S. Denzler

Electric Power Research Institute 3412 Hillview Avenue

P.O. Box 10412

Palo Alto, CA 94303

Attn: Bhupen (Ben) Mehta
Louisiana Geological Survey (3)

University Station; Box G

Baton Rouge, LA 70893

Attn: C. G. Groat

W. J. Autin

Brigid Jensen

Mississippi Department of Environmental Quality; Office of Geology

Attn: S. Cragin Knox

P.O. Box 20307

Jackson, MS 39289

Injection and Mining Division (8)

Louisiana Office of Conservation

P.O. Box 94275, Capitol Station

Baton Rouge, LA 70804-9275

Joe L. Ratigan

RE/SPEC, Inc.

3824 Jet Drive

Rapid City, SD 57709

Amoco Production Company

Exploration Department

501 West Lake Park Blvd.

P.O. Box 3092

Houston, TX 77253

Attn: William Hart

Rudy Begault

The MITRE Corporation

800 Commerce Road East, Suite 201

New Orleans, LA 70123

R. G. (Bob) Haley

Union Texas Petroleum

P.O Box 440

Port Allen, LA 70767

Harry G. Allison

Golden Strata Services, Inc

711 Louisiana, Suite 1600

Houston, TX 77002 
Mr. Ben Knape

Texas Water Commission

1700 N. Congress Ave.

P.O. Box 13087 Capitol Station

Austin, TX 79811

Prof. Saul Aronow

Department of Geology

Box 10031

Lamar University Station

Beaumont, TX 77710

PB-KBB Inc (2)

11767 Katy Freeway

P.O. Box 19672

Houston, TX 77224

Attn: Karl M. Loof

B. E. Russell

Solution Mining Research

Institute

812 Muriel Street

Woodstock, IL 60098

Attn: H. Fiedelman

Texas Bureau of Economic Geology (3)

University Station, Box X

Austin, TX 78713

Attn: W. L. Fisher M.P.A. Jackson

S. J. Seni

Joseph D. Martinez

3641 S. Lakeshore Drive

Baton Rouge, LA 70808

T. R. Magorian (8)

133 South Drive

Amherst, NY 14226

L. S. Karably

Law Environmental, Inc.,

223 Townpark Dr.

Kennesaw, GA 30144-5599
R. L. Thoms (5)

AGM, Inc.

P.O Box 10358

College Station, TX 77842

D. H. Kupfer

7324 Menlo Drive \#3

Baton Rouge, LA 70808

A. H. Medley

1716 S. 75th E. Ave.

Tulsa, OK 74112

R. Ginn, Coordinator

Underground Injection Services,

Environmental Services

Railroad Comm. of Texas

Austin, TX 78711-2967

Sandia Internal:

6000 D. L. Hartley

6100 T. W. Lynch

6113 J. K. Linn (10)

6113 S. J. Bauer

6113 B. L. Ehgartner

6113 T. E. Hinkebein

6113 P. S. Kuhlman

6113 R. V. Matalucci

6113 J. T. Neal (15)

6113 J. L. Todd

6117 W. R. Wawersik

6214 H. J. Sutherland

6217 D. H. Zeuch

6217 J. C. Lorenz

6217 D. S. Preece

7141 Technical Library

7151 Technical Publications

7613-2 Document Processing (10) for DOE/OSTI

8523-2 Central Technical Files (3)

Bayou Choctaw SPR Site

$60825 \mathrm{Hwy} .1148$

Plaquemine, LA 70764

Attn: M. Slezak 
Big Hill SPR Site

P.O. Box 1270

Winnie, TX

Attn: Jim Perry

Bryan Mound SPR Site

P.O. Box 2276

Freeport, TX 77541

Attn: H. Bakhtiari

Weeks Island SPR Site

P.O. Box 434

New Iberia, LA 70560

Attn: M. Bertoldi

West Hackberry SPR Site

1450 Black Lake Road

Hackberry, LA 70645

Attn: P. Hetznecker 

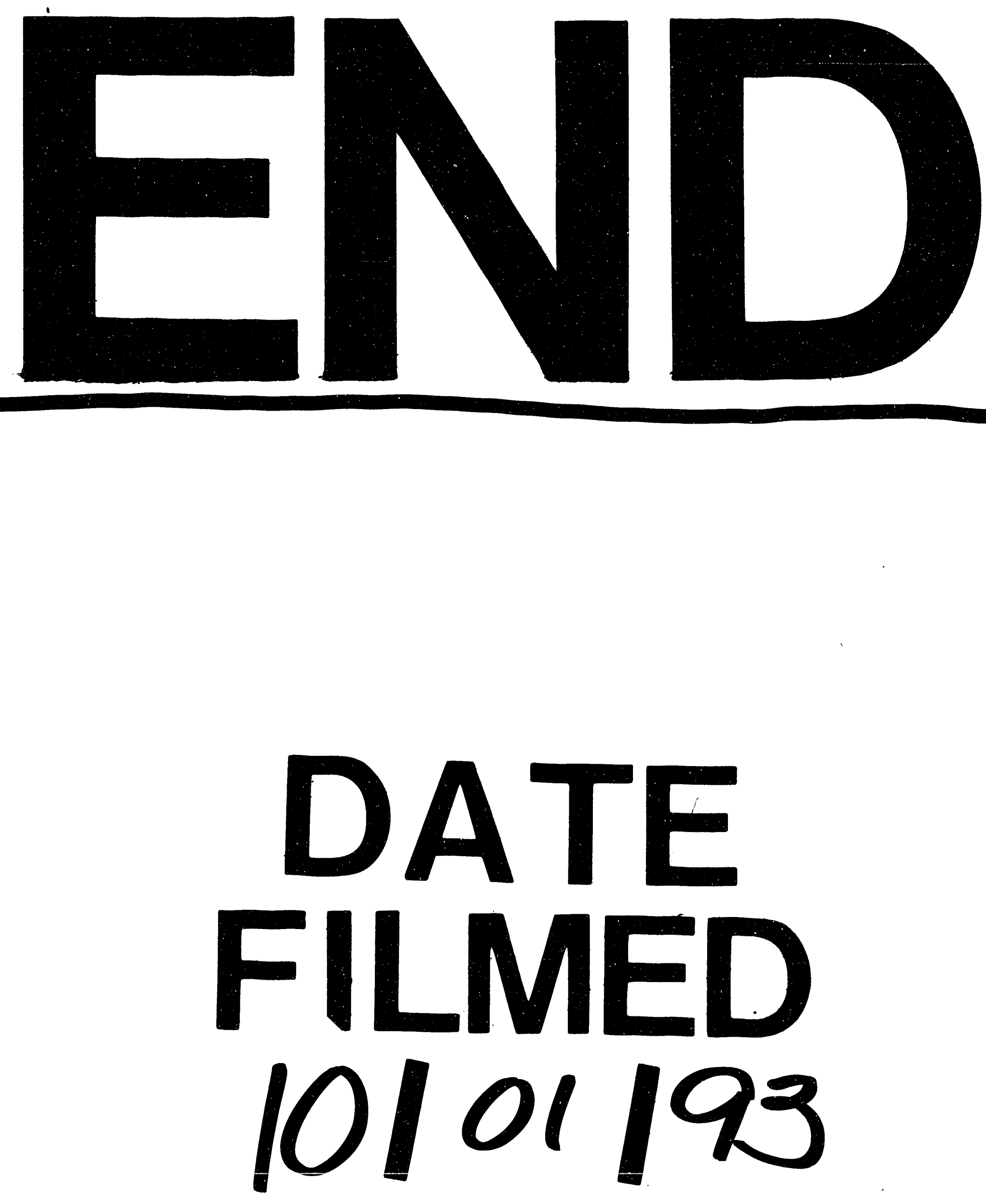
